\title{
الاتصال والتواصل في منظومة مجتمع المعرفة: \\ نحو رؤية إسلامية للتواصل الإنساني
}

\section{محمد بابكر العوض* - مح}

$$
\begin{aligned}
& \text { الملخص } \\
& \text { تتكون الرؤية الاتصالية لأية بحموعة بشرية من الروابط التي تشكل العلاقات بين الرؤية الحضارية لتلك البمموعة، العافي }
\end{aligned}
$$

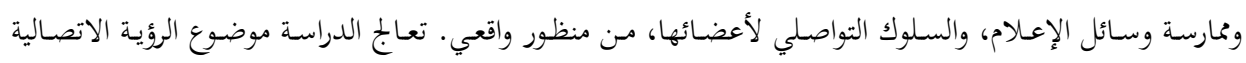

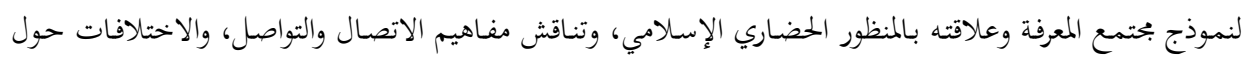

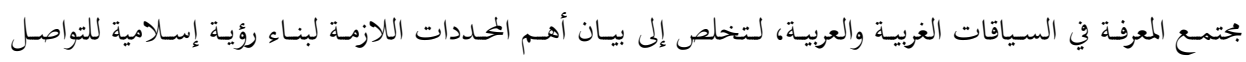

$$
\begin{aligned}
& \text { الإنساني. } \\
& \text { الكلمات المفتاحية: الاتصال، التواصل، بحتمع المعرفة، الرؤية إسلامية، التواصل الإنساني، رؤية العالم، التمركز } \\
& \text { اللغوي، الاغتراب الحضاري، الأنساق المعرفية. }
\end{aligned}
$$

\section{Communication in the system of knowledge society: Towards an Islamic perspective of human communication}

\section{Abstract}

Communication perspective of any society consists of relations that constitute civilizational vision of that society, communicative behavior of its members, and the media practices. This study deals with the communication perspective of the knowledge society and its relationship with the Islamic cultural perspective. It discusses the various concepts of communication, and differences in understanding the knowledge society between the Western and Arab contexts. It concludes with identification of the most important determinants of Islamic perspective of human communication.

Key words: communication, knowledge-based society, Islamic perspective, worldview, Language centrism, cultural alienation, epistemological patterns.

$$
\begin{aligned}
& \text { * دكتوراه في علوم الاتصال، أستاذ الإعلام وعلوم الاتصال المشارك- عميد معهد إسلام المعرفة (جامعة الجزيرة)، } \\
& \text { mohd702002@yahoo.com }
\end{aligned}
$$

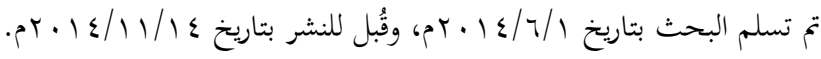


مقدمة:

قد تبدو القضية الاتصالية -للوهلة الأولى - أمراً طارئاً على الفكر الإنساني؛ مرتبطاً في أصل وجوده بالطفرة التقنية التي تعيشها المجتمعات الإنسانية المعاصرة، في حين ينتمي

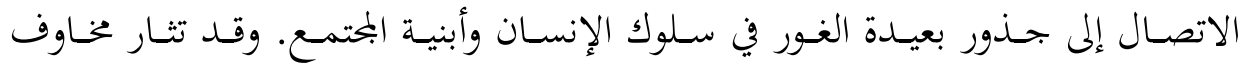

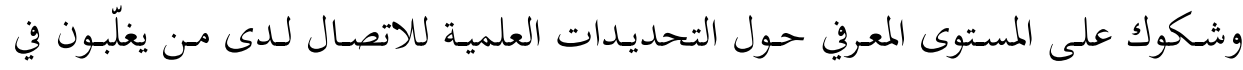
تعـاملهم معسه جانـب النظر بوصفه سـلوكاً إنسـانياً وظـاهرة ميزة للمجتمعـات الإنسـانية المعاصـرة، متناسـين أثنـاء ذلك أن الاتصـال قـد غـدا فرعاً معرفيـاً فتيـاً آخــاً في التكوّن، ودائباً على فرض وجوده على الساحة المعرفية.

ولعل استعراض مراحل تطور الفكر الاتصالي المعاصر يعين على استكشاف الأسس

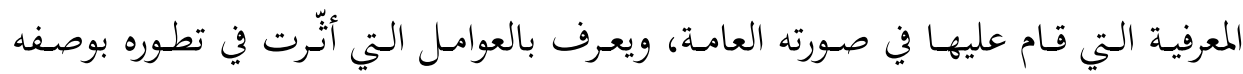
حقلاً معرفياً حديث النشأة في البيئات العربية والإسلامية. وهو ما يستدعي وعياً منهجياً قادراً على استيعاب المزايا العلمية لمعطيات الفكر الاتصالي السائد، وبحاوز ما يشوبه من علائق معرفية ونظرة سالبة ولّدتما بيئة المنشأ الغربي أو بيئة الموطن الجديد.

وقد شهد العقدان الأخيران من القرن العشرين تركيزاً ملحوظاً على موضوع (المعرفة) وعلاقتهـا بـالتطورات النابحـة عـن ثـورة التكنولوجيـا والاتصـالات، والتغـيّرات الاجتماعيـة والاقتصادية المصاحبة لما، كما أكدت الخبرات البشرية منذ فجر الإنسانية على المضمون

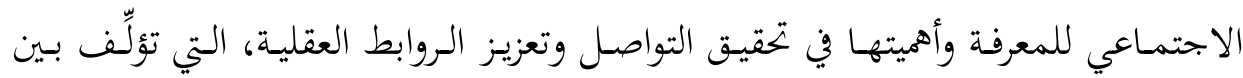
الناس وبتعل التفاهم بينهم مكناً. ومهـدت تلـك الفكـرة الموروثـة عـن التواصل المعـرفي المؤثَّلـة بنـواتج الفكــ الاتصـالي

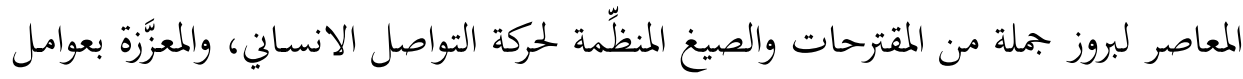
دوليـة جديـدة؛ منهـا عولمـة النظـام الاقتصـادي، والسـي إلى استـدامة التنميـة، والمنافسـة 
القوية بين شبكات الاتصال وشركات التقنية في توسيع نطاقات عملها واكتساب عملاء جدد، والخوف من المستقبل.

وقـد أسهمت تلك العوامـل بحتمعـة في ظهـور مـاعــف بالنظـام الإعلامي العـالمي الجحديد، الذي لم تمض عقود حتى تبلور تحت شعار العولمة، بحســاً أهـم ظـاهرة دوليـة

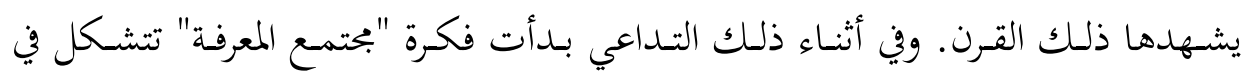

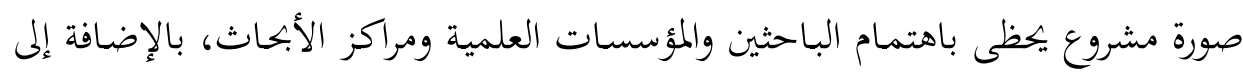
انشغال الحكومات والمنظمات وناشطي المحتمع المدلي بالمنافسة المحمومة، في سبيل تحقيق أكبر قـدر مـن تطبيقـات تقنيـات الاتصـال والمعلومـات وتوظيفاةهـا، التي تمثل المعطيـات الأولية لقيام النموذج.

ومن البـدهيّ القول إنَّ التعـايش الواعي مـع هـذه المنظومـات أو عَبْرهـا أو خارجها، واتخاذ موقف يتّسـم بالموضسوعية والرشــ مـن أطروحاتها، يتطلـب -ابتـداء- وجـود رؤيـة

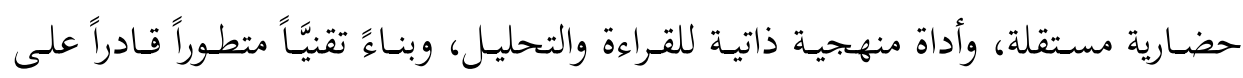
مواكبة تطورات البيئة التواصلية للاجتماع الإنساني والتفاعل معها بإيجابية. ويفرض هذا الأمر على مختلف المحتمعات ومنها بحتمعات العالم العربي والإسلامي، إعادة النظر في نماذج التحديث السائدة -كنموذج بحتمع المعرفة-، والانتباه للتحديات والتطورات الحادثة في واقع الاتصال الإنساني ومواكبتها بالقراءة والتقويم، واختبار مناهج

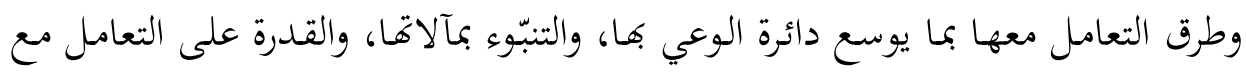
انعكاساتا وآثارها المترتبة على حياة البحتمعات والأفراد.

وتقوم المنهجية المقترحة لهذه الدراسة على افتراضٍ أسـاسِ بـأن نموذج بحتمع المعرفة يعـود في أصسوله التكوينيـة إلى جـذور وجوديـة "أنطولوجيـة" ضـاربة في العمـق، تنتمي إلى مرحلة مـا قبل التقنيـة، وإلى جـذور معرفيـة "إبستمولوجية" تتـأثر بـالتطور المنهجي للعلم وأدواته، وجذور واقعية "إيكولوجية" تخضع للتفاعل المباشر مع الواقع المحسوس. 
ومــار الدراسـة كمـا يشـير عنواهـا ثلاثـة مفـاهيم هـي: مفهـوم الاتصـال، ومفهـوم

التواصل، ومفهوم بحتمع المعرفـة. ويُشـيرُ الأخير إلى الصلِِِ الاجتماعيـة المُتزايدةِ للمعرفـة

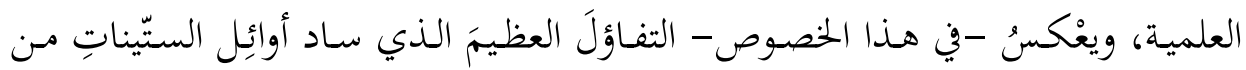
القرن العشرين. وإذا عددنا "دانيال بيل" من أوائل من عرَّف بمفهوم بحتمع المعرفة، فإننا

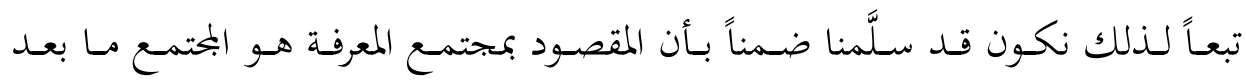
Manuel الصناعي. ويشير الأكاديمي البريطاني "ديلانتي" إلى تحليلات (مانويل كاستلز

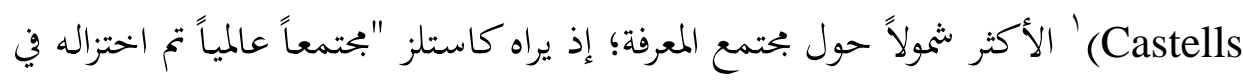
حدود قياسات الدولة القطرية". وربما تم تعريف بحتمع المعرفة بوصفه المجتمع الذي تحركه التطورات الجديدة في محال تكنولوجيا الاتصال والمعلومات، أو بأنه نموذج أكثر ديمقراطية من المحتمعات التي تتأسس على إمكانات ديمقراطية. وبعامَّة يمكننا القول إنَّ بحتمع المعرفة

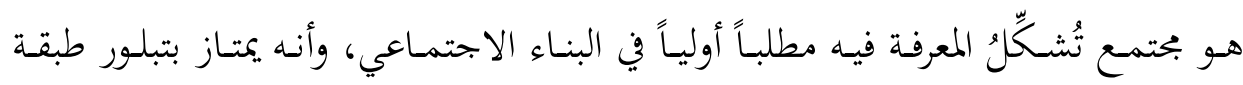
جديدة مـن المشتغلين بمجالات إنتـاج المعرفة ونشرها وتوظيفها، وأنه يهتم بإعطاء قيمة اقتصادية للمعرفة.

وعـادة مـا يتـأثر تحليـل ظواهر الاتصـال بنـوعين مـن المتغـيرات؛ الأول معريّْ يتعلق بالتطور العلمي والمنهجي. والثاني فني تقني، يرتبط بالتطورات التكنولوجية. ويلاحظ أن

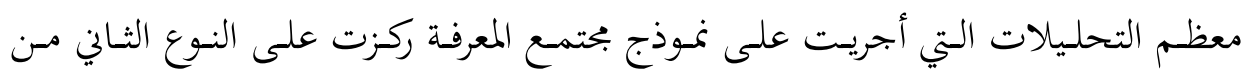
التطورات، في حين أن الرؤية الاتصالية التي يستند إليها النموذج ذات طابع معرفي يجعلها

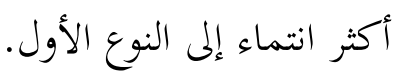
وقد تواضعت أدبيات البحث الاجتماعي على أن دراسة الظاهرة التواصلية قد مرت خلال تطورها بتحولات جوهرية تتمثل في مرحلة المجتمع الجماهيري، الذي يعكس حالة التخوُّف الأول من أثر وسائل الاتصال على البناء الاجتماعي، لتأتي بعده حقبة تعكس

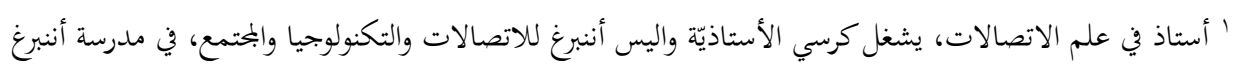

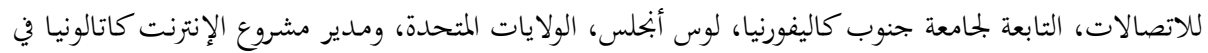


نظريـات الاتصـال السـائدة فيها تَقُّقق الوعي بتـأثيرات الاتصـال السـلوكية والاجتماعيـة. وتحوي هذه نوعين مـن النظريات؛ الأولى تعبِّ عن التأثير غير المحدود لوسائل الاتصال، وأخرى مقابلة لما تتحدث عن التأثير المحدود والمشروط للانتقال المُمَرْحَل للمعلومات. وفي المرحلة الأخسيرة -التي تشـير إليها الأدبيـات الاتصـالية في مرحلة انتشـار الاتحاهـات التحليلية والنقدية- تنتهي المسيرة لمرحلة راهنة تتمثل في نموذج بجتمع المعرفة وانعكاساته الاقتصادية والتقنية الاجتماعية، وهي مرحلة تستقطب باحثي الاتصال على نحو لافت، وإنْ لمُ يتحقق إجماع حولما بَعدُ.

ولا شـك في أن لتحفظ بعض الاتجاهـات العلمية في عالمنا العـربي والاسـلامي على تأسيس الدراسـات الاجتماعية والإنسانية على التجربة الغربية قدراً مـن الوجاهـة، إلا أن الرجوع إلى الحيثيـات التاريخيـة لتلك التجربـة لا يفقـد أهميته في مثل دراستنا، مـا دام قـد ثبـت أن "بحتمع المعرفة" - كمـا هو مُتـاوَل - مشـروع غربي المنشـأ، وحلقـة مـن حلقـات التطور المعرين للمجتمعات الحديثة في نستختها الغربية. ومـن تمح فإن تحديد موقف علمي منه يظل رهناً بأخذنا له في سياقه الموضوعي والتاريخي، وهو ما يلزمنا بالرجوع إلى التجربة التاريخية والمعرفية التي تولَّد عنها.

ويزخر رصيد المعرفة الاتصالية الحديثة بمعين غنيِّ بالمقاربات وأطر التحليل المتحدة في موضوع عملها، والمتباينة في تركيبها ومـداخلها المنهجية. وتُعدّ نماذج الاتصـال التقليدية هي أول هذه الأطر على مستوى علوم الاتصال، ׳ُوهي بالتأكيد سابقة تاريخياً لشيوع

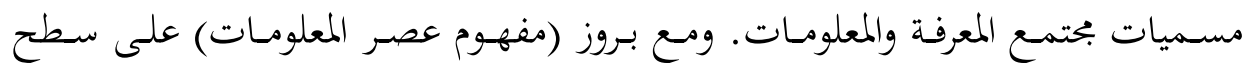
الاهتمام العلمي وازدياد الدراسات في هذا البحال وتكاثفها، برزت محاولات إيجاد معايير

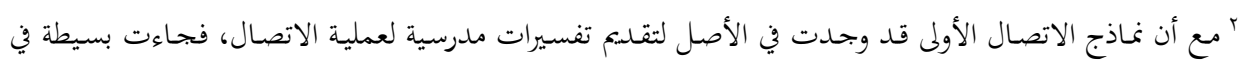

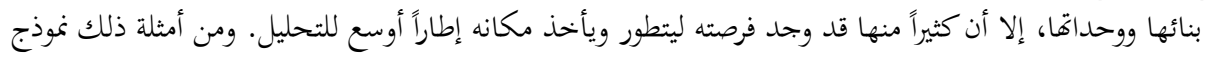

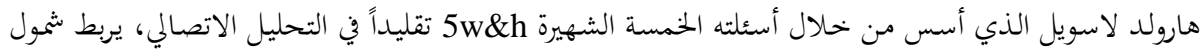

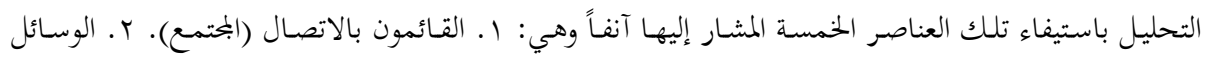

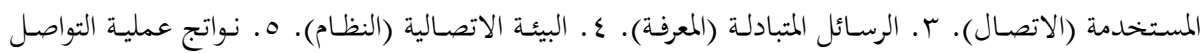




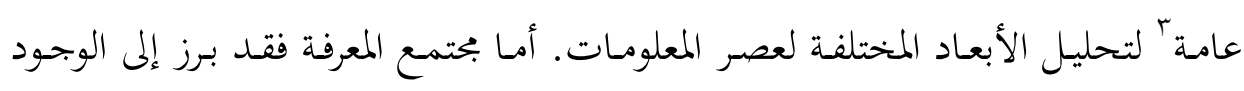

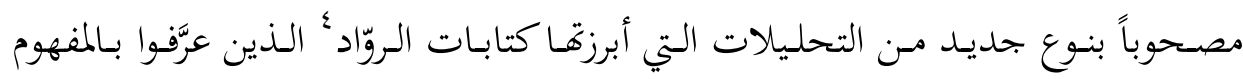

r سعى باحثون أمريكيون ويابانيون وأوربيون لاستخلاص معايير عامة لتحليل عصر المعلومات بمراجعات كثيفة لعدد

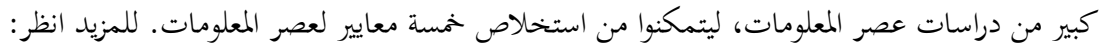

- Martin, W .J. The Information Society. London: Aslib. The Association for Information Management , 1988 , P.40.

؛ تتسم تحليلات رواد الفكرة (دانيال بيل وبيتر دروكر ومانويل كاستلز) بكوفا مقاربات علمية (أكاديمية في أغلب

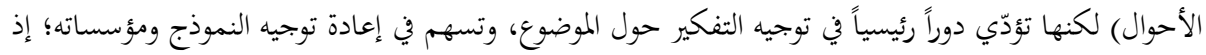

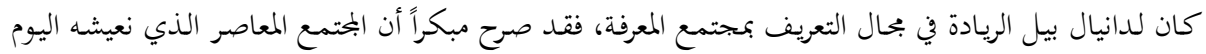

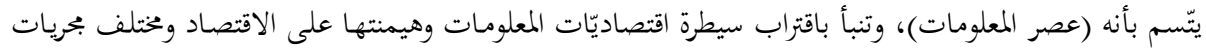

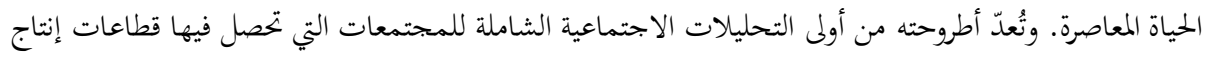

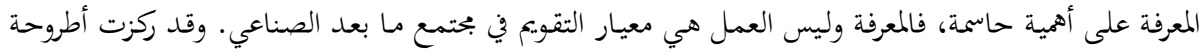

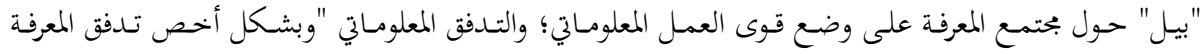

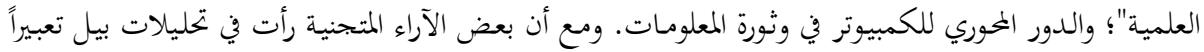

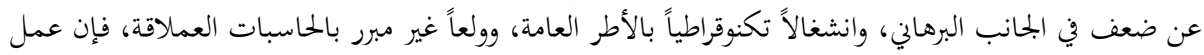

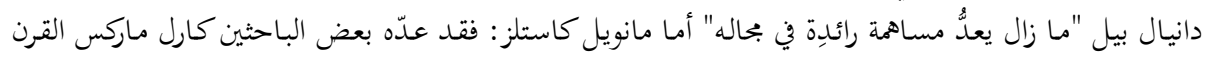

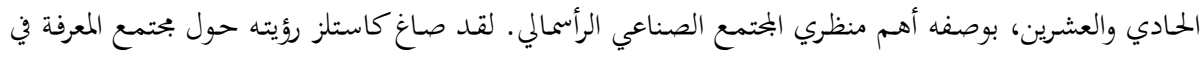

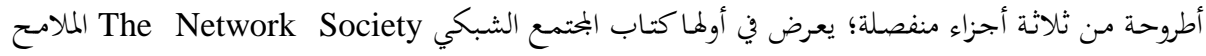

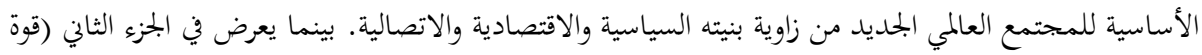

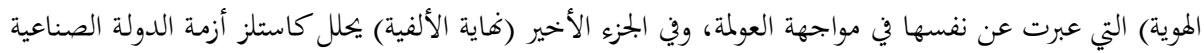

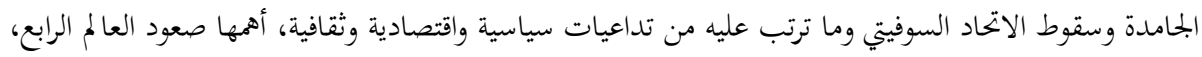

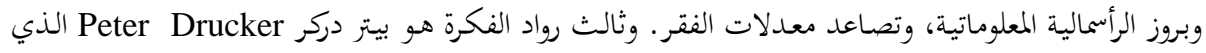

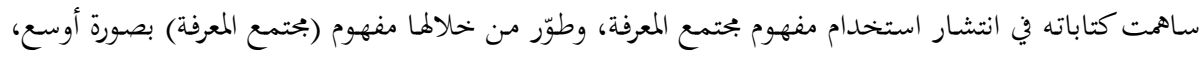

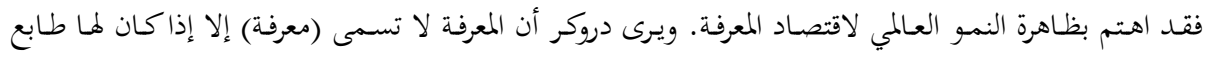

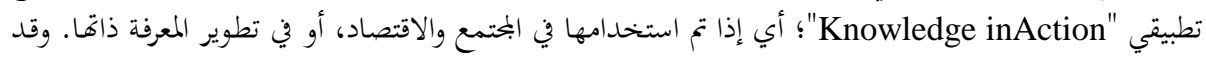

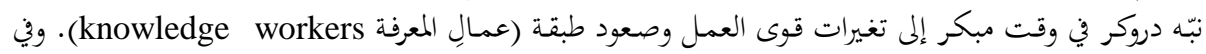

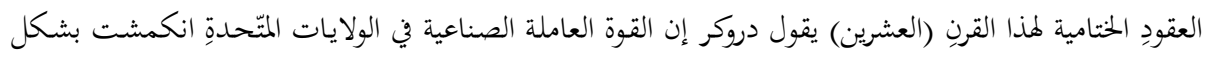

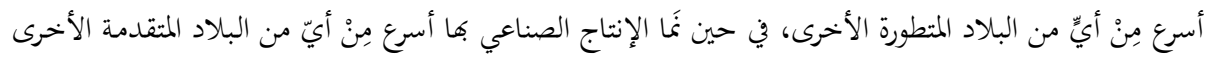

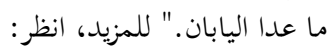
- يسن، السيد. الهوية في مواجهة العولمة، صحيفة المصدر الفيان الإعلامي الحر. http://www.freemediawatch.org/81-010706/8.htm

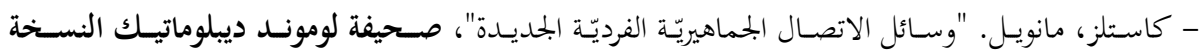

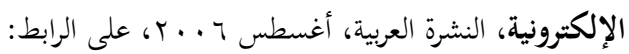
http://www.mondiploar.com/article412.html?PHPSESSID=2f20e3214aa4ab7a5777008a 
وروَّجحوا له، وكان رواد الفكرة ينتمون إلى حقول معرفية مختلفة، وإن اشتركت في انتمائها إلى مساق العلوم الإنسانية والاجتماعية. ولكن عندما تحوّل المفهوم إلى واقع فعلي يستند

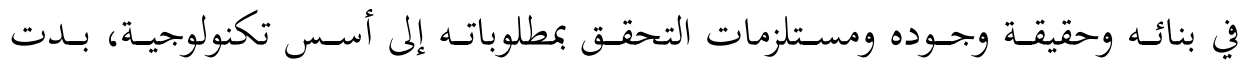
التحليلات القادمة من القطاع التقني تتخذ مكاناً ميزاً، لا في حدود التحليل فحسب بل بل بـ على مسـتوى وضـع سياسـات الاتصـال الدوليـة والمحليـة، التي أصبح لشـركات الاتصـال

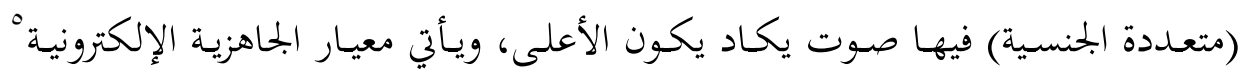
واحداً من الأطر القادمة من هذا الأفق.

- Bell, Daniel. The Coming of Post-industrial Society. New York: Basic Books, 1999.

- Böhme, Gernot and Stehr, Nico. The Knowledge Society The Growing Impact of Scientific Knowledge on Social Relations, Springer, 1986. p 9

- Smeby, Jens-Christian. Professionalism in a knowledge society: The academic drift of professional education in the "new" professions, Centre for the Study of Professions Høgskolen i Oslo Oslo University College Working paper no. 07/2006 www.hio.no/sps,p8

- Drucker, Peter. The age of Discontinuity. New York: Horper and Row. 1969. P.269.

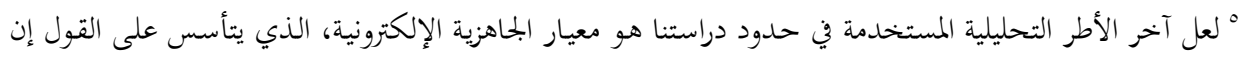

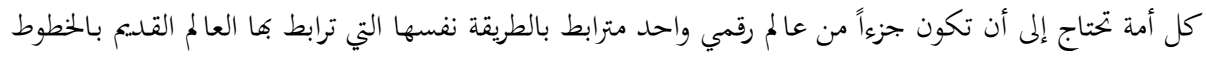

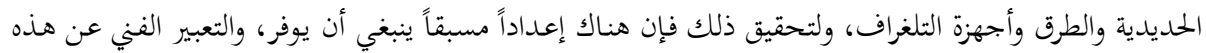

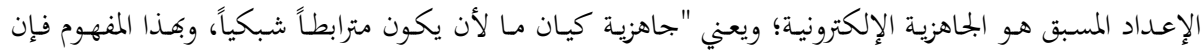

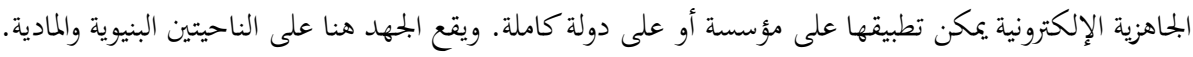

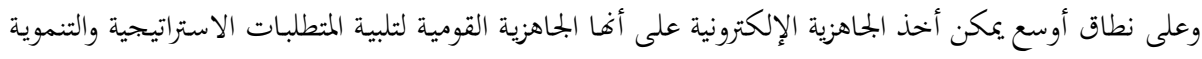

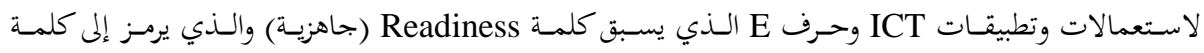
Electronic

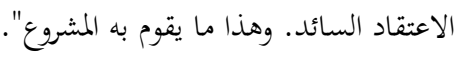

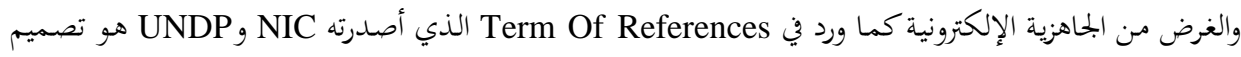

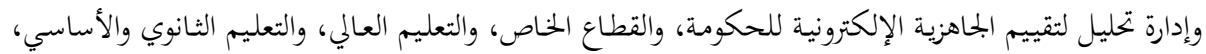

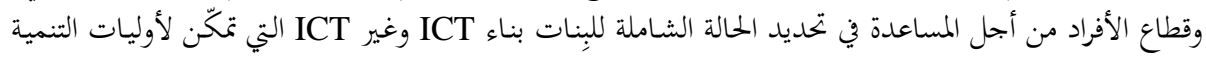

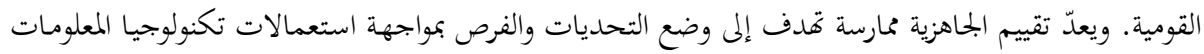

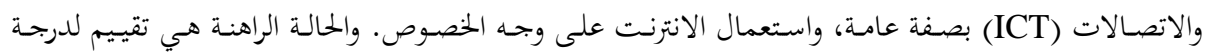

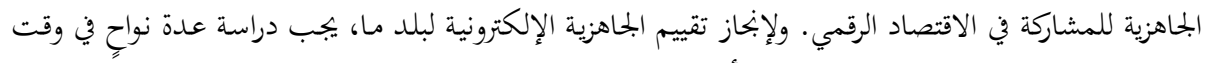

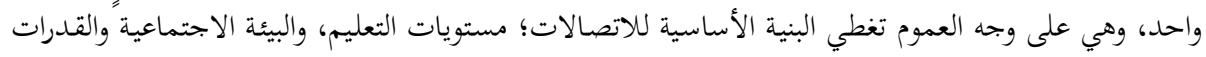

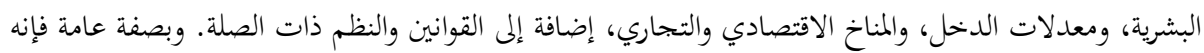


ولتحديد الموقف من الأُطُر السابقة ومدى إمكانية الاستفادة منها، لا بدّ في البدء من تبنّي إطار نظري متكامل لدراسة البنية الاتصالية للمنظومة؛ إطارٍ تتكامل فيه الجوانب التفسيرية والتحليلية، على نحو يمنحهـ القـدرة على تحديد الأبعاد النظرية والفلسفية لهذا الواقع، وما يتعلق منها بالرؤية الحاكمة للنظام، وأبعادها الثقافية والاجتماعية، وما يرتبط بهـا مـن قـرارات، وأبعادهـا التطبيقيـة، ومـا يتعلـق بالآليـات المسـتخدمة في إدارة النظـام وتشـيله، وهي المحاور الأكثر حضـوراً في المحاولات السـابقة لدراسـة التطورات الراهنـة للنظام الاتصالي الدولي.

يتميـز نمـوذج بحتمـع المعرفـة بسعة الانتشـار على رقعـة جغرافيـة شاسعة؛ إذ تمـت

مراجعته ونقـده مـن قبل عـدد مـن البحتمعات التي سبقت إلى النظر في النموذج والحكـم عليه. وتحتاج المجتمعات الإسلامية لرؤية في بحال الاتصال تحفظ لها خصوصيتها وتميزها عن المجتمعات الأخرى، كما حدث في بجالات الاقتصاد والاجتماع والسياسة؛ لأن البنى النظريـة الاتصـالية التي تم تطبيقهـا في عالمنـا لم تفلـح في الوفـاء بالاحتياجـات التواصـلية لإنسان هذا العالم.

ومع تنامي الاهتمام بالنموذج في بلادنا؛ فما زالت المنطقة العربية تُعدُّ منطقةَ ظلِّ في خارطة دراسات بحتمع المعرفة، فهي بعيدة عن الجزء النشط من الإطار الحيوي للتفاعل

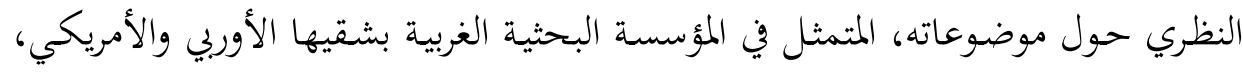

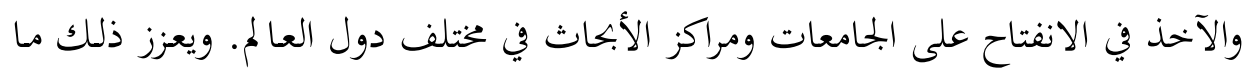

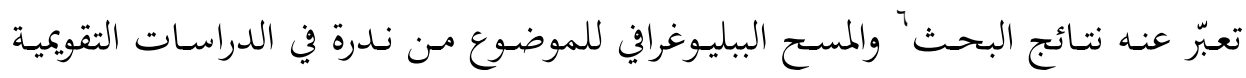

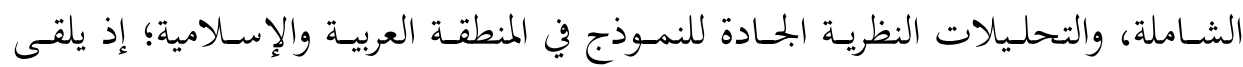
الاهتمام بتحقيق المطالب التقنية والاقتصادية للنموذج وتطبيقاته من الأولوية والاهتمام ما لإنهاي لا يلقـاه التقويم العلمي والمنهجي للجهـود المبذولـة في هـذا الابجـاه. وعليـ؛ فبإن بوسعنا

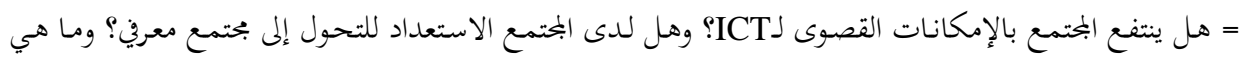

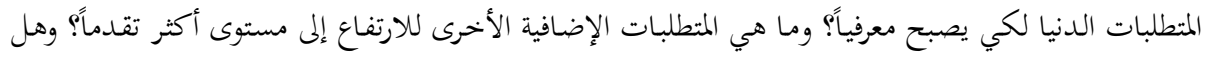

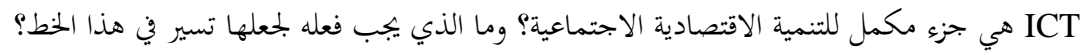

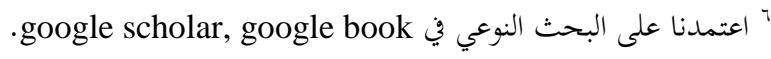


القول إن غاية ما يسعى له هذا التحليل هو الوصول لآلية منهجية منضبطة، تساعد في قراءة بحتمع المعرفة في ضوء معطيات ومقتضيات الواقع العربي الإسالامي. يسعى البحثث عمليـاً لتعزيز موقع الوظيفة المعرفية، لتكون ضمن الوظائف الأكثر أهمية وإلحاحاً في سُلَّم أولويات التواصل في المحتمعات الإسلامية المعاصرة، تلك التي تنزَّل

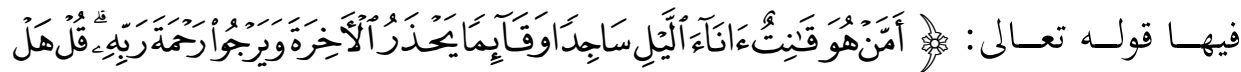

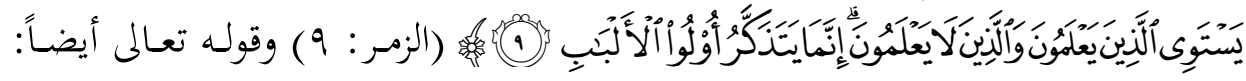

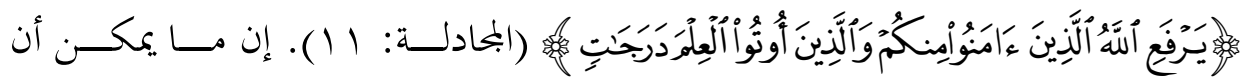

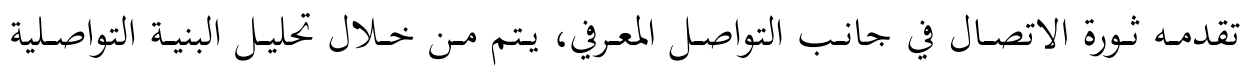

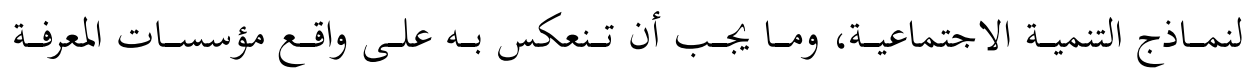
كالجامعات والمدارس والمراكز العلمية والثقافية، التي تعدّ من أهم مؤسسات بحتمع المعرفة؛ وكذلك الإجابة عمّا يثار من تساؤلات منهجية حول الموضوع من قبيل:

ما هو موقع نظرية بحتمع المعرفة في سياق الفكر الاتصالي المعاصر؟ وما ملامح كل من الأطروحة النظرية والرؤية الاتصالية لنموذج بحتمع المعرفة؟ وما هي الأبعاد الاجتماعية والاتصالية لنموذج بحتمع المعرفة؟ ومنهجياً تعتمـد الدراسـة مـدخلاً إبستمولوجيا، فيـه مكان لتحليل المفـاهيم والأطر النظرية والأصول المعرفية للظواهر. كما استفادت من المنهج الوصفي التحليلي، لما يمتاز به من إفادة في جوانب وصف الواقع الفعلي للظاهرة وتفسيرها، واهتمام بتحديد الظروف

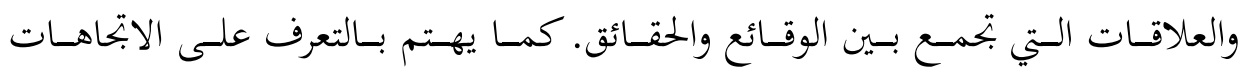
والمعتقدات وطرائق نموها وتطورها، وكلها مزايا تحتاجها الدراسة.

وقـد جـاء تقسيم الدراسـة في خمسـة محاور؛ تبـدأ بمحسور مفـاهيمي ينـاقش موضـوع الجحل حول مفاهيم الاتصال والتواصل. ويعالج المحور الثاني معنى بحتمع المعرفة ودلالاته في السياقين الغربي والعربي. ويقدم المحور الثالث رؤية تحليلية لنموذج بحتمع المعرفة. ويف المحور الرابع يتم عرض رؤية العالم بوصفها الأداة الأنسب لتحليل الرؤية التواصلية. ويأتي المحور الأخير ليعرض أهم محددات بناء الرؤية الإسلامية للتواصل. 


\section{أولاً: جدل الاتصال والتواصل}

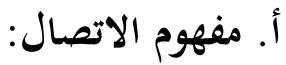

تبدو اشكالية المفاهيم في هذا العلم أوضح ما تكون حين تثير كلمة اتصال -لشيء

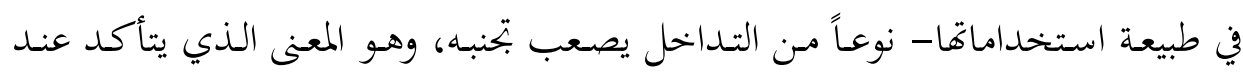

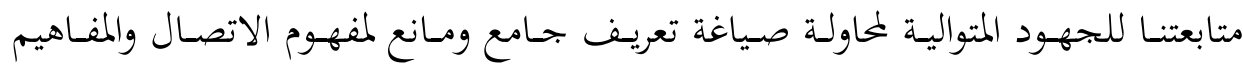

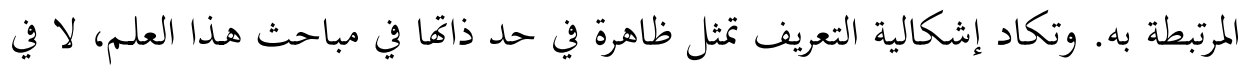
صورته العربية فحسب بل حتى في داخل العلم الاتصالي الغربي نفسه. وقد عملنا في دراسات سابقة على تتبع سيرة مفهوم الاتصال في السياقين العربي والغربي عبر استعراض

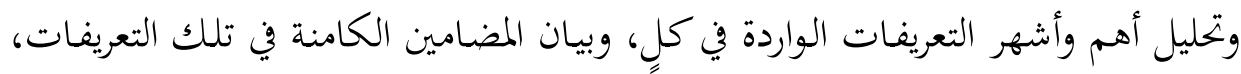

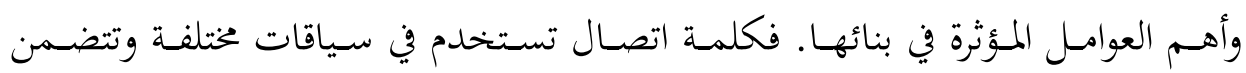

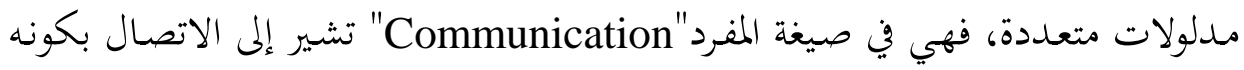

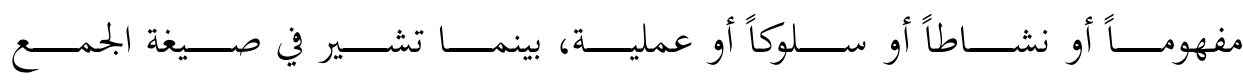
"Communications"

ويلاحظ أن هناك تداخلاًا آخر بين مفهوم الاتصال وتقنيات الاتصال الشخصي والهواتف بأنواعها. فعندما أراد الناقد والفيلسوف الأمريكي بورك "Burke" طبع كتابه المعنون: أطروحات عن الاتصال Treaties on Communication، اضطر في النهاية لتغيير العنوان لتخوُّف الناشر من أن القراء سيرونه دراسة عن الهواتف.

إذا رجعنا إلى جذور الاستخدام اللغوي، فسنكتشف أن مفهوم الاتصال في الثقافة

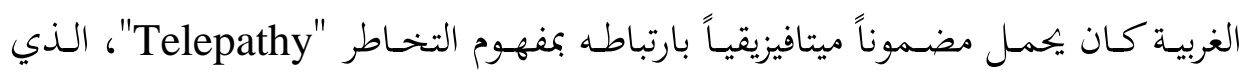
يعني تبادل الأفكار دون وسيط.

V مكاوي، حسن عماد، والسيد، ليلي حسين. الاتصال ونظرياته المعاصرة، القاهرة: الدار المصرية اللبنانية، طع،

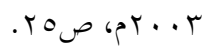

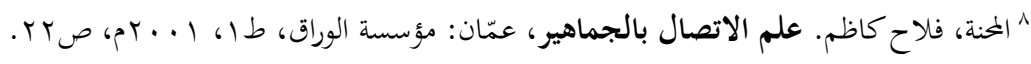


وتشترك الحضارات الشرقية في إضفائها على الاتصال بُعداً داخلياً ومسحة روحية.

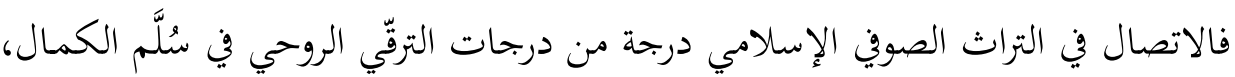

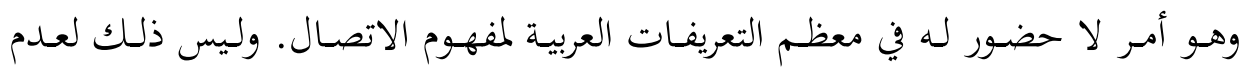

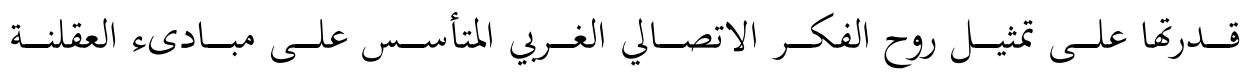
"Rationalizing" والعلمانيـة فحسبـ، بـل لفشـلها أيضـاً في استيعاب التراث (العربي الإسلامي) الذي يحتوي على تحليلات عميقـة لجوانب أساسية في عملية الاتصال، مثل الإدراك، واكتساب المعاني، والإقناع، وتغيير الاتجاهـات، التي يمكن استقاؤها مـن أعمال ابن الطفيل وابن رشد والبيروني وابن الصانع وغيرهم.

ويبدو التداخل بين المفـاهيم الاتصـالية أكثر بروزاً في الدراسات العربية، حين تقدم

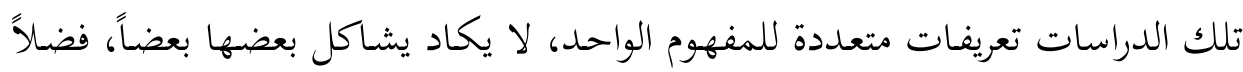

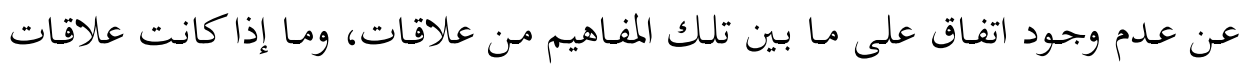
ترادف أوتباين. ومرجع هذا الاختلاف هو نشوء المفهوم الاتصالي في بيئة معرفية مغايرة من ناحية، وضعف عملية الاستيعاب والتمثّل للعلم الاتصالي ومفاهيمه في البيئة العربية. وربما تعلّق الأمر بحداثة نشأة علوم الاتصال حتى في بيئتها الأصلية.

ومن ثم واجه المفهوم في الدراسات العربية إشكالات يتعلق بعضها بالترجمة عن اللغة الأصل، التي هي في غالب الأحيان الإبحليزية أو الفرنسية. وسنلاحظ في الفقرات الآتية

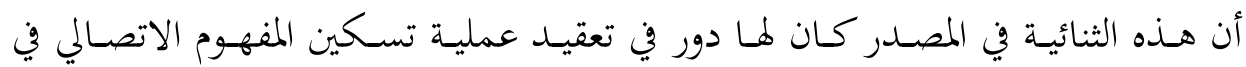

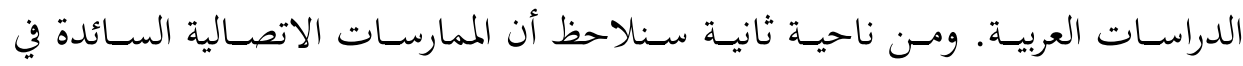
المجتمعات العربية، التي لا تحفل بهـا بحـوث الاتصـال الغربية، تظل غائبة بمفاهيمها عن

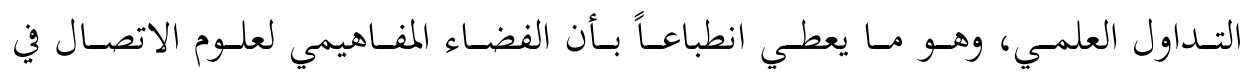
الجامعات العربية يعبّر عن مضامين الاتصال الغربي أكثر من تعبيره عن واقع الاتصال في البحتمعات العربية نفسها.

وقد هيئ لهذه الكلمة "اتصال" أن تعبر من اللاتينية إلى الثقافة العربية المعاصرة عن طريق معبرين رئيسيين؛ هما اللغة الإبحليزية واللغة الفرنسية. والتغريق بين المصدرين مهم، لماليكان 
له من انعكاسات لاحقة على شكل الترجمة ومضموها. ففي المشرق العربي ترجمت كلمة Communication

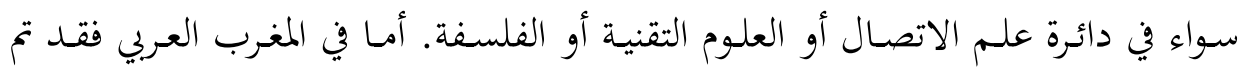
التفريق بين الاستخدامين؛ فعلى مستوى العلوم التقنية يتم استخدام "اتصال". وبعض مـن ترجمـوا الكتابـات الإعلاميـة عـن الفرنسية استخدموا كلمـة "اتصـال". أمـا في نطـاق الدراسـات الفلسفية وغالب الدراسـات الإعلاميـة وبقيـة العلوم الإنسـانية فظل التفضيل لاستخدام كلمة "تواصل"

ويمكن وصف المحاولات العربيـة لتعريف الاتصـال بأهـا تصـدر عن قراءة سكونية للمفهوم؛ إذ تنظر إلى مفهوم الاتصال من موضعه "الإبستمولوجي" الذي اتخذه بعد عزله

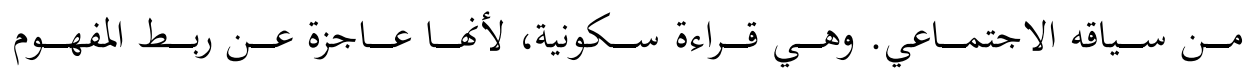
"الإبستمولوجي" الفـوقي بجـذوره الاجتماعيـة الـدنيا، وتقدمـهـ في إطـار القـوانين الداخليـة

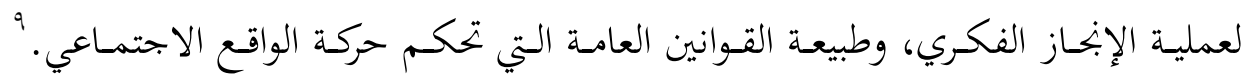
وظلَّت هذه القراءة العربية للمفهوم تؤكد عجزها عن صياغة تعريفات مستقلة، قادرة على العى التعبير عن واقع الظاهرة الاتصالية في البحتمعات العربية.

إن الفصـام القـائم في العقل الأكـاديمي العربي بـين الاطـار النظري لعمله، ومـا تمـت صياغته غربياً، والواقع الاجتماعي المعيش الذي يفترض أنه يمثل المحيط الموضوعي لعمله،

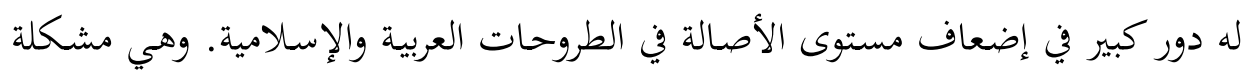
بنيوية ترتبط بتكوين الباحث نفسه أكثر من ارتباطها بعملية التعريف في حد ذاتما. ومما بحدر ملاحظته أن حقل الإعلام والاتصال يجظى بما يشبه الإجماع على أهميته

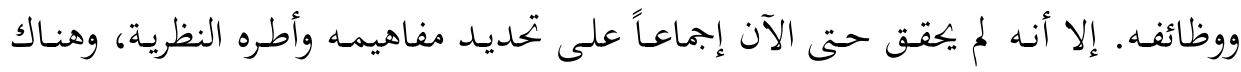

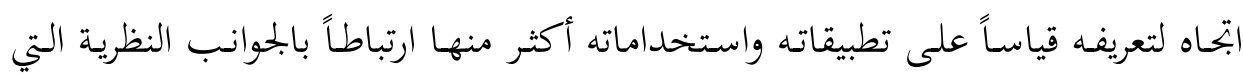
تسمح لنا بنقد هذه الاستخدامات وتقييمها.

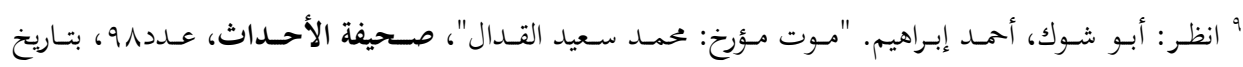
. . . . . 
وتبعاً لما سبق يمكن تعريف الاتصال بأنه:

وصفُ لعلاقة قائمة على نوع من الاستعداد الذهني بين شتص أو أكثر، يسمح بتحقيـق قـــر مـن الاشـتراك والتبـادل والنقـل للمـدركات والمواقـف الشـعورية أو الصـور الذهنية، باستخدام الحواس وامتدادتها التقنية من الوسائل الاتصالية المختلفة.

ويشمل الاستعداد الذهني: وجـود إطار دلالي مشترك، أو إطلار مـن الخـبرة المشتركة بين أطراف العملية الاتصالية. واستخدام مهارات الاتصال الأساسية والمكتسبة (السمع والكلام - القراءة والكتابة) ونهوها.

ونعني بالاشتراك: إيجاد أو التحقق من مستوى المعرفة المشتركة بين أطراف العملية. أما التبادل، فنعني به: الانتقال المتبادل للمعرفة بين أطراف العملية. ويشير النقل إلى انتقال المعرفة مـن طرف لآخر بقصد الإخبار والإعلام أو التعليم والتدريب.

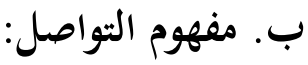

يقصد بالتواصل: "السلوك الاتصالي الموجبب بين أطراف العملية الاتصالية، الناتج

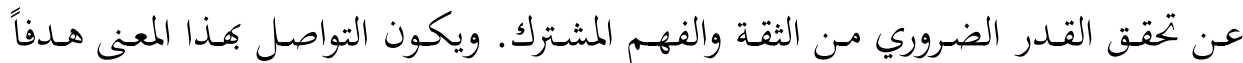

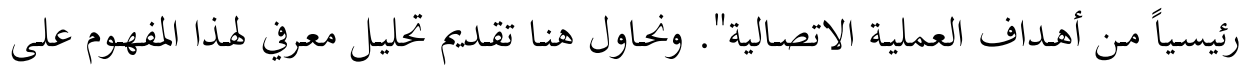
نهوٍ يضعه في سياقه، في الوقت الذي يجد فيه الأفراد أنفسهم في بيئة جديدة ليست لهم

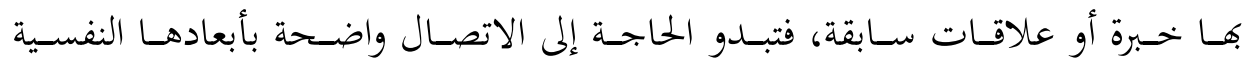
والاجتماعيـة؛ إذ إن الشعور بالعزلـة والاغـتراب يزيـــ مـن الـوعي بتلك الحاجـة التي تـأتي كغيرها من الحاجات الإنسانية مصحوبة بقدر من التوتر النفسي، الذي يزول بزوال المؤثر وتحقيق إشباع تلك الحاجة.

وقـد يكـون التواصـل مشـتركاً في بعض دلالاتهـ مـع التقبّل الاجتمـاعي، والتعـارف،

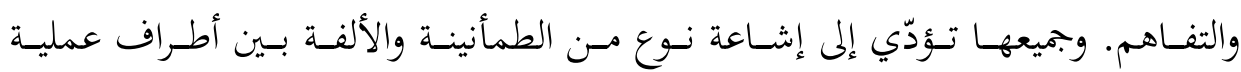




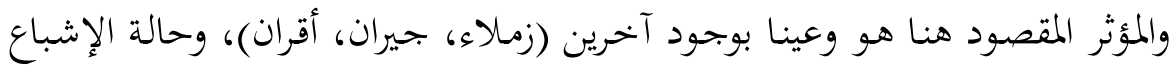

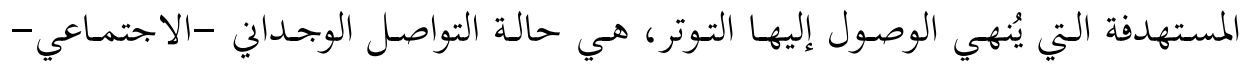

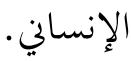

إننا طوال ممارستنا ومشاركتنا في عمليات الاتصال المختلفة، نسعى للتحقق من أننا

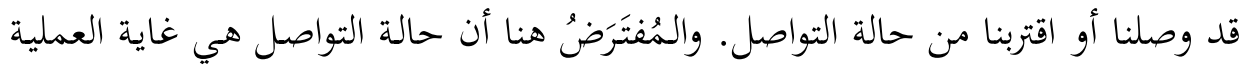

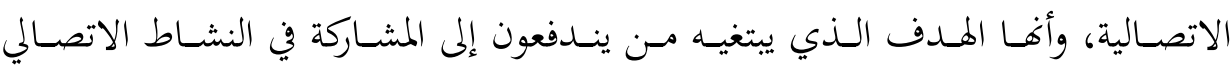

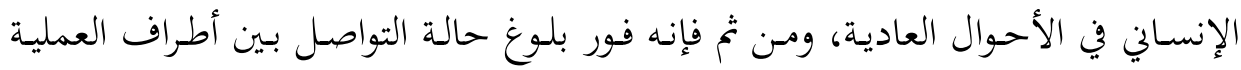
الاتصالية يتحقق الاستقرار، ويتهيّأ ظرف أكثر إيجابية لإبناح عملية الاتصال.

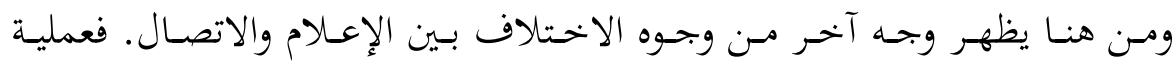

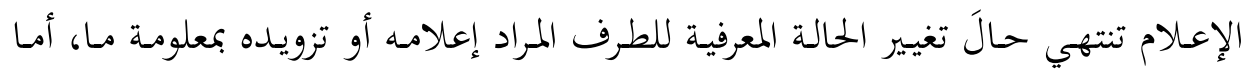
الاتصال فهو عملية مستمرة، تسعى باتحاه بناء علاقة (معرفية، اجتماعية، وجدانية)بين

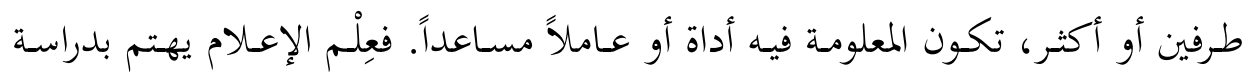

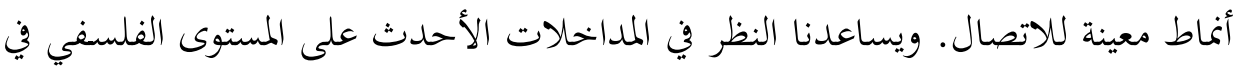

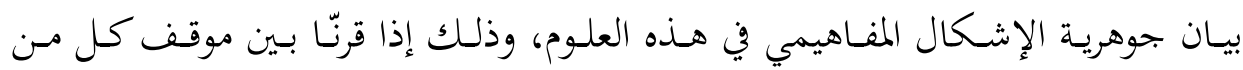

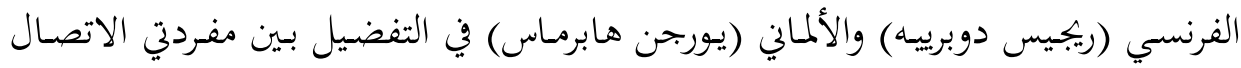

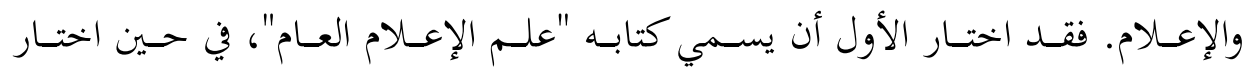
الفيلسوف الألماني هابرماس مفهوم "الفعل التواصلي".

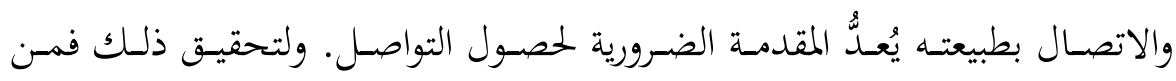

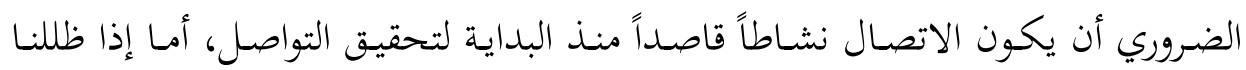

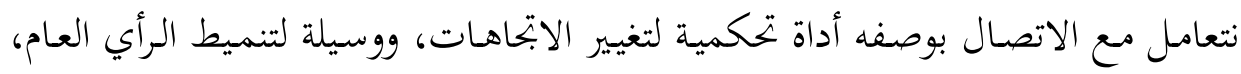

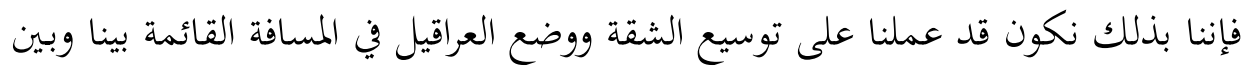
تحقيق التواصل المنشود.

وإذا عـدنا إلى الواقع ونظرنـا في مفارقة ضعف التواصل مـع ضـامة البنيـة التقنيـة

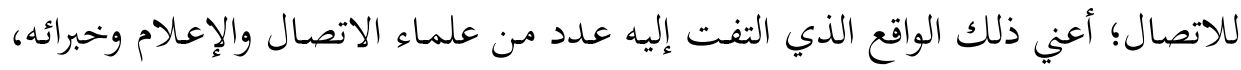


الذين تحوي أعمالهم تعبيرات بليغة في وصف الحالة، منها (وسائل الاتصال التي تكرس العزلة) وعبـارة (اتصـال بـلا تواصل)، التي انطلق منهـا البحـث، تبـيّن لنـا مقـدار التشـابه والاختلاف بين مفهومي الاتصال والتواصل، وانتهى بنا إلى ما خن فيه الآن.

وفي البحـوث الاسـتطلاعية حـول المفهـوم في سـياقاته اللغويـة والاجتماعيـة، تظهـر

القرائن التي تربط المفهوم بأبعاد روحية ميتافيزيقية. وإجمالاً لما سبق فإن الملاحظة تحيل إلى أن ثمة عوامل كان لها دور بـارز في خلق نوع من الضبابية على الفضاء المفاهيمي لعلوم الاتصال بعامة، من أهمها: - المان

- - الحداثة النسبية لظهور الاتصال على أنه علم قائم بذاته. - شدة التداخل بين مباحث علم الاتصال والعلوم الأخرى. - تسارع وتيرة التطور في بحال تقنيات الاتصال المعاصرة ونُظمها. ومن أبرز العوامل التي أسهمت في تكريس هذا الوضع في البيئات العربية: - - نشوء هذا العلم في بيئة معرفية مغايرة (بيئة العلم الغربي). - - الاختلاف في لغة مصدر المعرفة العلميـة الاتصالية بين اللغة الإبحليزية واللغـة الفرنسية. - - الاعتماد على جهود الأفراد في ترجمة المصطلحات والكتب المرجعية في بحال

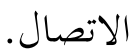

ويتوقع -مـع تزايــ الالهتمـام بالحقـل الاتصـالي واتسـاع دائرة المشـتغلين بـه، ودأب باحثيه ومؤسساته العلمية على تأكيد شخصيته بوصفه علماً قائماً بذاته- أن تتجه بنيته المفاهيمية وقاموسه الاصطلاحي لاكتساب ملامح أوضح. وتتمثل أبرز الإشكالات النابتحة عن هـا الوضع، في العجز الذي تبديه دراسـات وبكوث الاتصـال المعاصـرة حيـال الواقع العـربي الإسـلامي، وضـفف قـدرقا على العمل بذات الفعالية التي عملت بها في بيئاةا الأصلية. وقد اكتفينا في هذا الجزء -أثناء محاولتنا 
إعـادة قراءة المفهـوم الاتصـالي - بـالنظر في المفـاهيم المشتركة والأساسـية لدراسـة الظـاهرة الاتصـالية، واسـتبعدنا بـوعي، المفــاهيمَ ذات الارتبـاط بنظـام الاتصـال الإسـلامي (مثل مفهوم الـدعوة والاستجابة ...) وفـق منهجيـة في التحليـل، بتمـع بـين منـاهج التحليـل اللغوي والتحليل الإبستمولوجي لمفاهيم الاتصال. وللوقوف على العِلّة الكامنة وراء هذا

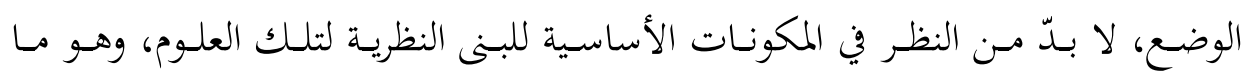
سيحملنا على استصحاب الرؤيـة النظرية الإسـلامية للاتصـال إذا صحح التعبير (أو رؤيـة

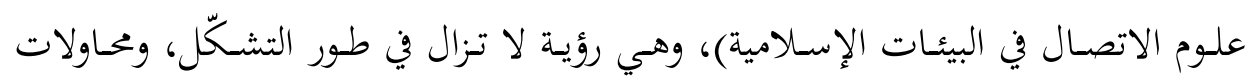
التعبير عن ذاها.

\section{ثانياً: في معنى مجتمع المعرفة}

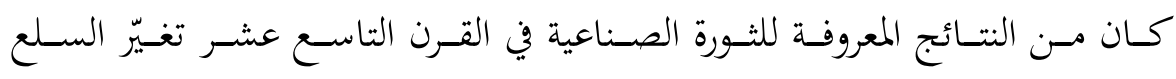
الاسـتراتيجية وقـوى الإنتـاج وعلاقـات الإنتـاج. فقبـل الثـورة الصــاعية كانست السـلعة

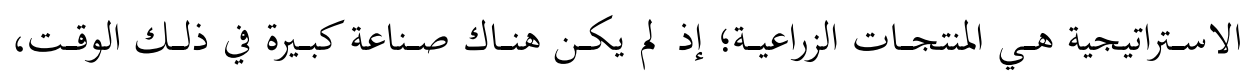
وكانـت قـوى الإنتـاج الرئيسية هـي المـزارعين، وكانـت علاقـات الإنتـاج هي العلاقـات

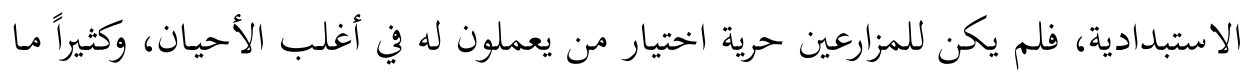

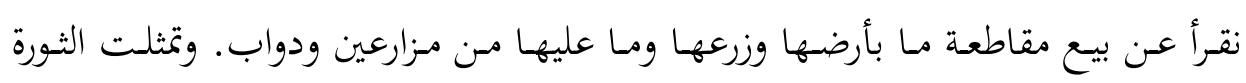

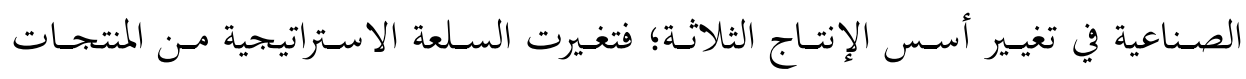
الزراعيـة إلى المنتجـات الصـناعية، وتحوّلت قـوى الإنتـاج الرئيسية مـن مـزارعين إلى عمـال

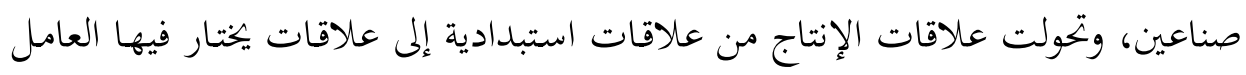

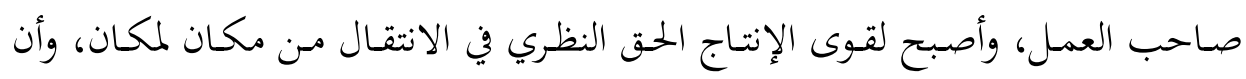

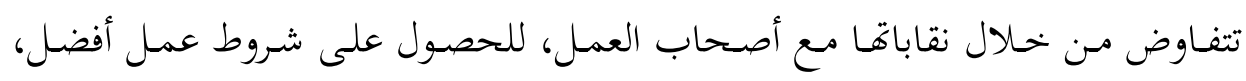
وظهرت فكرة ساعات العمل المحددة.

وما يحدث الآن هو بالتحديد تكرار لما حدث في القرن التاسع عشر . فقد تغيرت

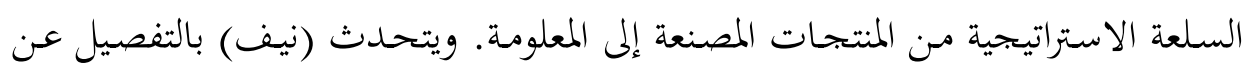


بحتمع المعرفة الحالي في الولايات المتحدة. ضارباً المثل بالشركات الأمريكية الجحيدة كشركة جوجل Google وغيرها، التي لا تنتج أي بضاعة مصنعة، ولكنها تحقق أرباحاً خيالية،

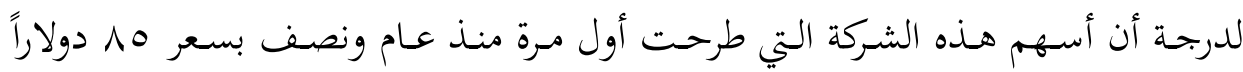

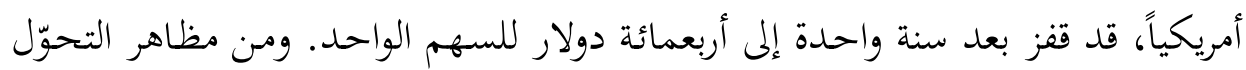
الاقتصادي الحالي ظهور قطاع ضخم من الشركات التي تنتج بربحيات حاسوبية متقدمة. والملاحظة المهمة التي يرصدها نيف (9191 1) وغيره، هو تحول الهيكل العام للاقتصاد

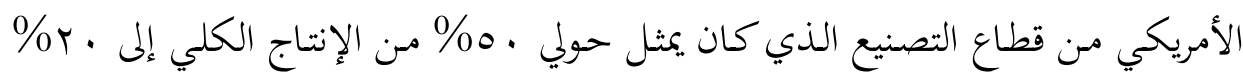

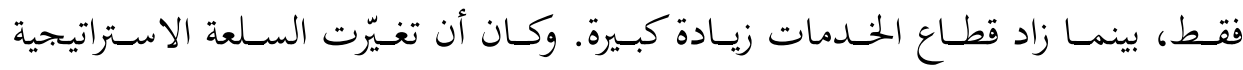
وأصبحت المعلومة؛ فقد تغيّرت قوى الإنتاج الرئيسية في المحتمع الأمريكي الحسالي إلى مـا

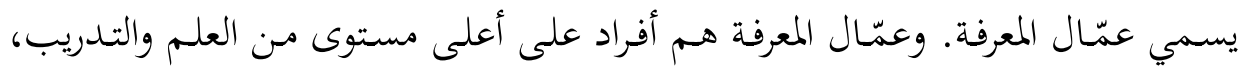

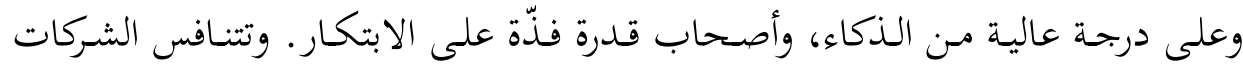

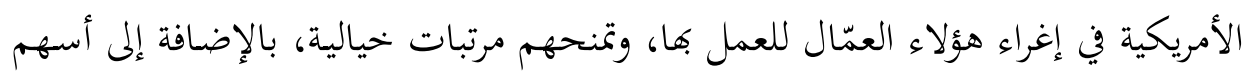
شبه بحانية في الشركات، حتى يعملوا بها كما لو كانت شركتهم الخاصة. هذه هي قوى الإنتاج في الثورة المعلوماتية، فعلاقات الإنتاج أصبحت علاقات شبه مشاركة في الرأسمال. أما الشركات الصناعية التي تنتج المنتجات الصناعية فيتم تصديرها إلى الخارج للاستفادة من رخص العمالة، والقرب من الأسواق العالمية. '1

وإذا اعتمدنا الرأي القائل إن "دانيال بيل" هو أول مـ عرّف بمجتمع المعرفة، فإننا

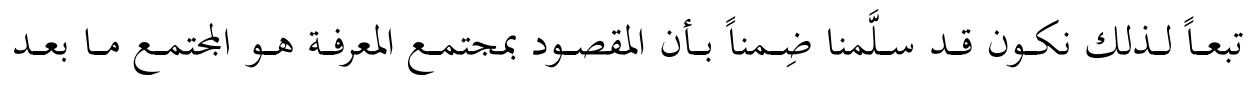
الصناعي.

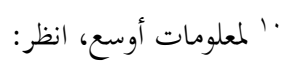

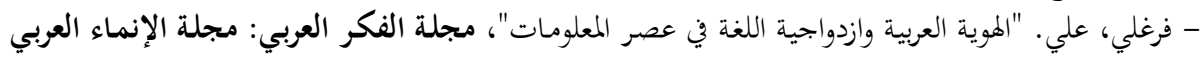

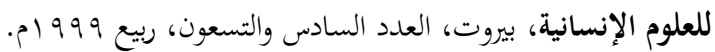

- Neef, Dale. Ed. The Knowledge Economy, Boston, Massachusetts: ButterworthHeinemann, 1988.

- Neef, Dale. A Little Knowledge is a Dangerous Thing. Boston, Massachusetts, Butterworth-Heinemann, 1999. 


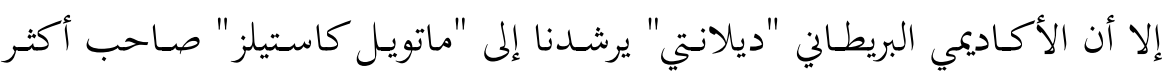

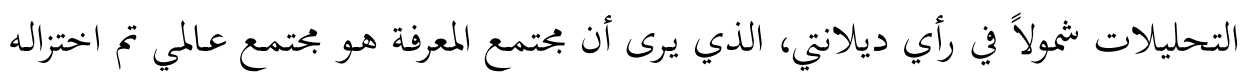
في حدود قياسات الدولة القطرية.

وربما تمّ تعريف بحتمع المعرفة بوصفه المجتمع الذي تخركه التطورات الجحديدة في بحال

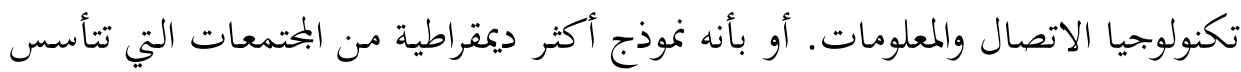

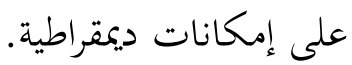

وبعامَّة يمكننا القول إن بحتمع المعرفة هو بحتمع: 1. تُشكّل المعرفة فيه مطلباً أولياً في البناء الاجتماعي.

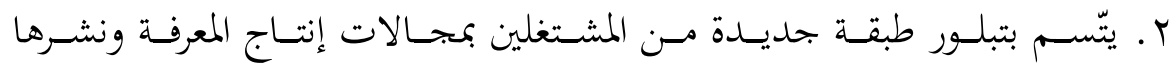

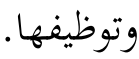

r. من سماته أنه يهتم بإعطاء قيمة اقتصادية للمعرفة.

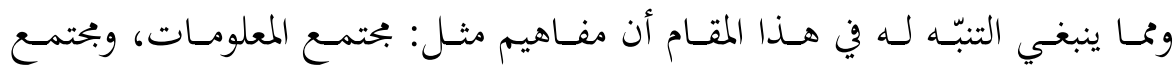

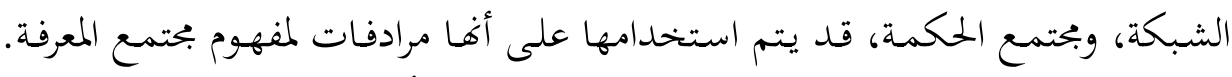

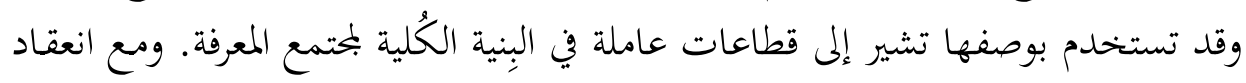

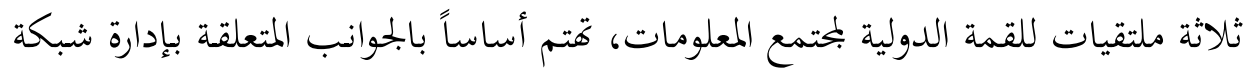

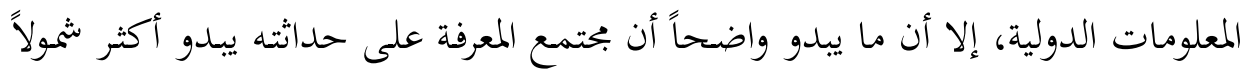

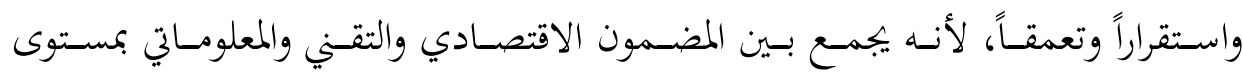

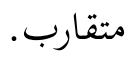

يعرِّف تقرير التنميـة البشرية المعرفـة بأهـا: "حجـم البيانـات والمعلومـات والحـبرات

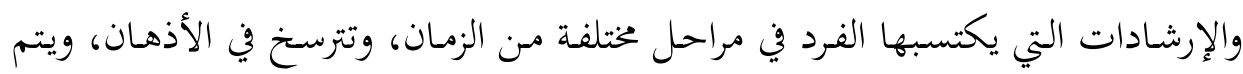

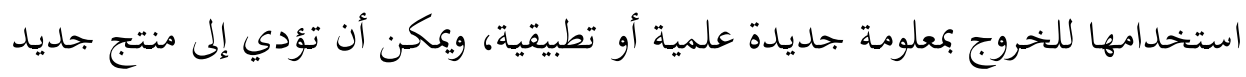

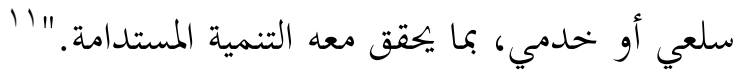

" "عبد الونيس، أمد،، وأيوب، مدحت. اقتصاد المعرفة، القاهرة: مركز دراسات وبكوث الدول النامية كلية الاقتصاد

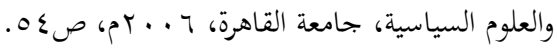


ثالثاً: الرؤية التحليلية لنموذج مجتمع المعرفة:

تتكون الرؤية التواصلية لدى أي جماعة بشرية من بحموعة الروابط المشكّلة للعلاقة

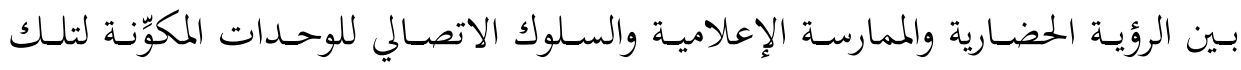

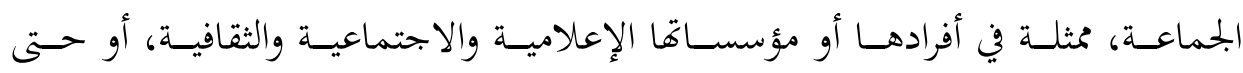

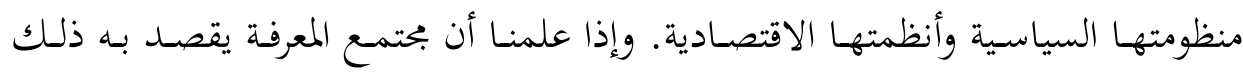

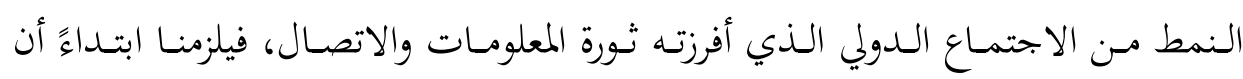

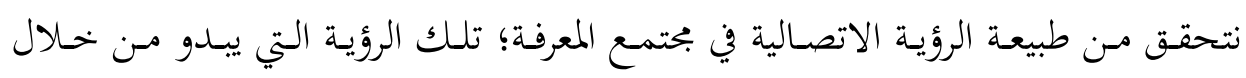

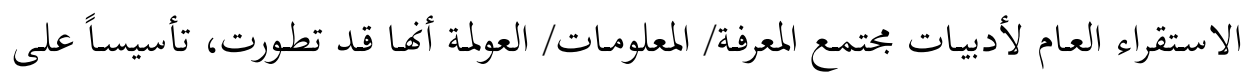

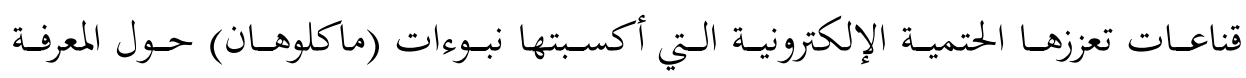

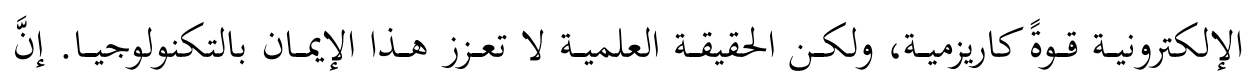
تقلص المسافات لم يقرب نفسياً بين الشعوب بل زاد في إبراز الفوارق وتعزيز العزلة.

\section{الإدماج والاندماج في مجتمع المعرفة:}

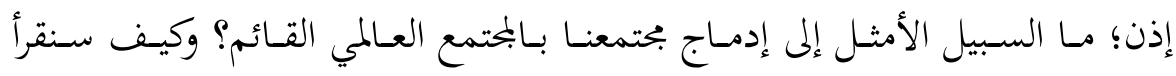

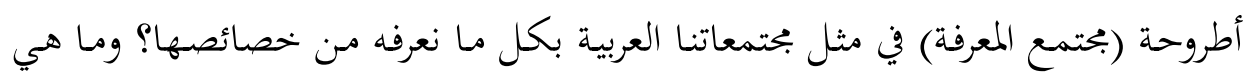
المداخل التي سنعتمدها لتحديد موقفنا منها؟

تتوقف الإجابة ابتداء على نوع ما نحمله من تصور بتحاه انتمائنا للمجتمع الإنساني

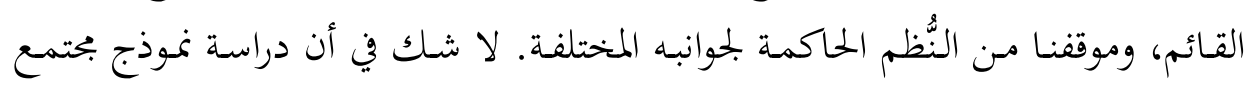

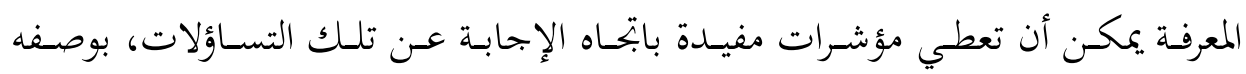

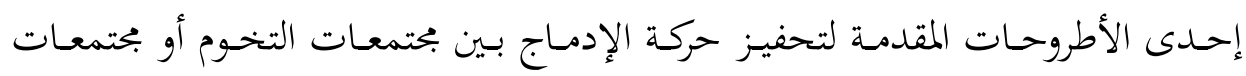
الهوامش، كما تسميها بعض الدروحات المغدة لحفيزت حركة

سيظل حديثنا عن عملية الإدماج محكوماً بالصيغة التي ورد بها السؤال، ولكننا نود

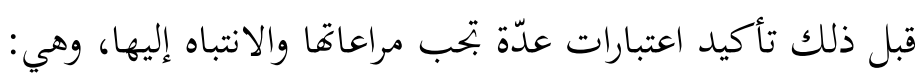




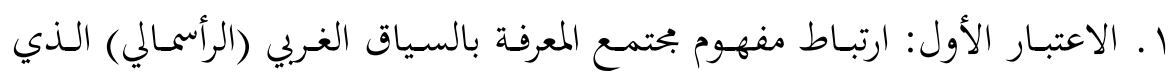

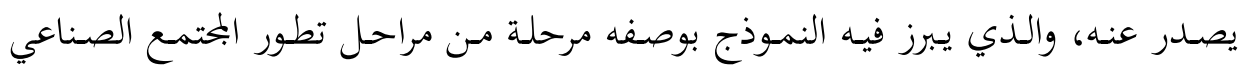
الغربي.

r. الاعتبـار الثـاني: مراعـاة التبـاين في الأفق الحضـاري الـذي يبتغي هـذا الـنمط

$$
\text { الاجتماعي الجحديد التمدد من خحلاله. }
$$

r. الاعتبار الثالث: الارتباط العضوي بين "بحتمع المعرفة" بوصفه مفهوماً نظرياً، وظاهرة العولمة على أهما حالة آخذة في الصيرورة على مستوى الواقع الإنساني.

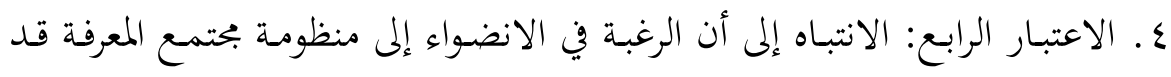

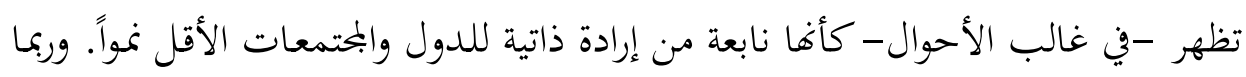

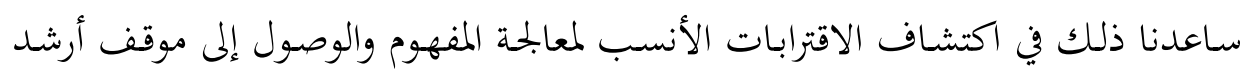

تجاهه.

\section{رابعاً: رؤية العالم أداة للتحليل}

كانـت أولى الشـكاوى مـن عـدم التـوازن في التـفقق المعلومـاتي والـدعوة لقيـام نظـام

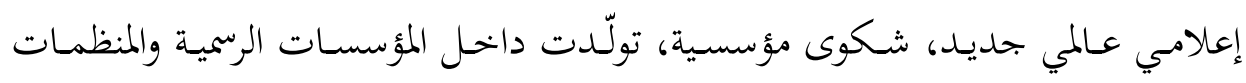

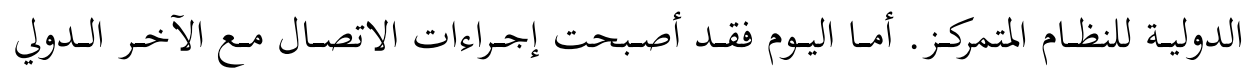

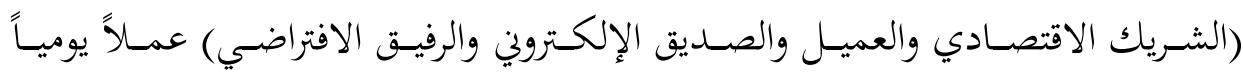

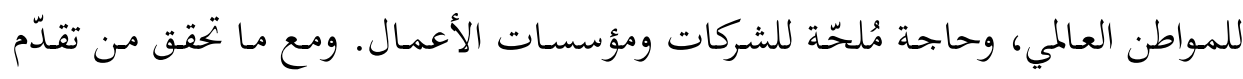

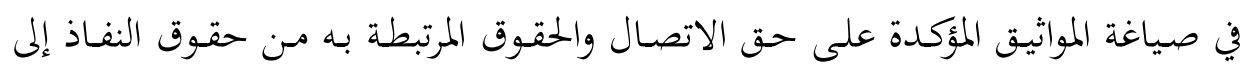

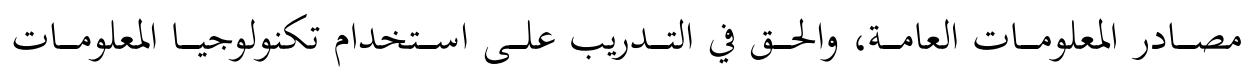

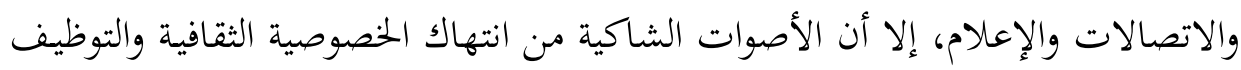

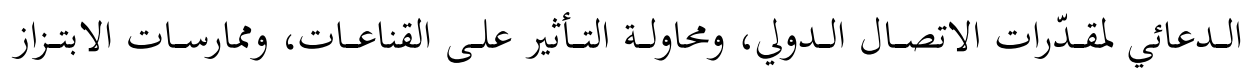

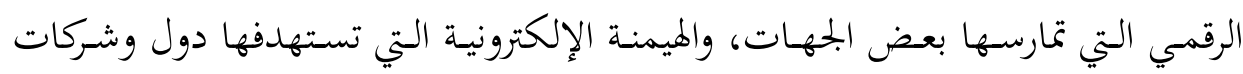

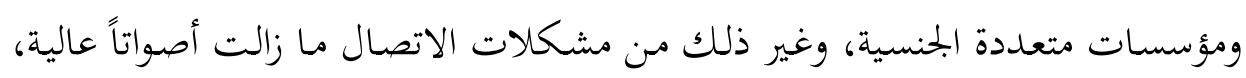




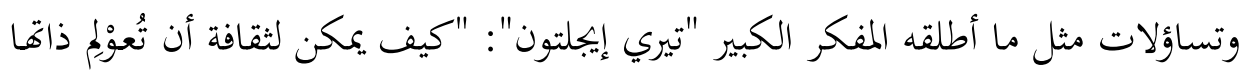

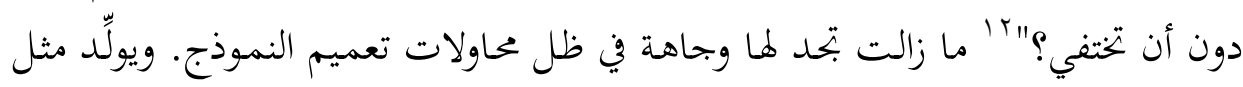

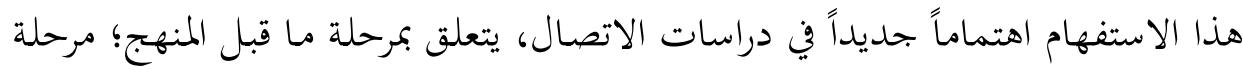

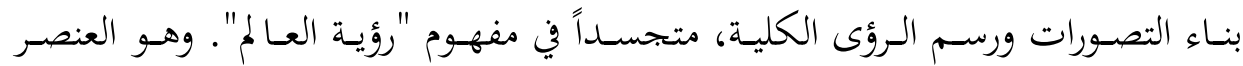
الغائب في جل الأطر التحليلية المشار إليها سابقاً.

يرى أصحاب تقرير (لجنة إدارة شؤون البحتمع العالمي) أن الانفتاح من خحلال وسائل

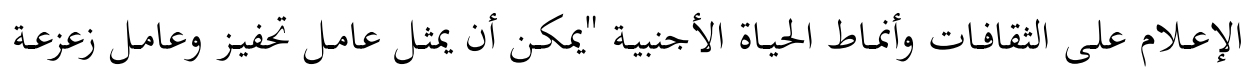

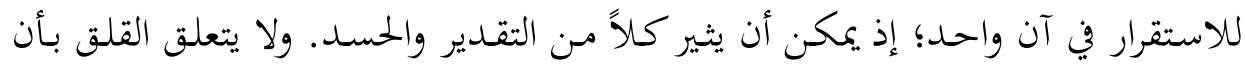

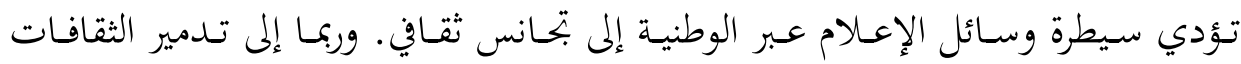

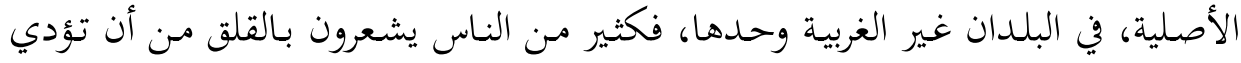

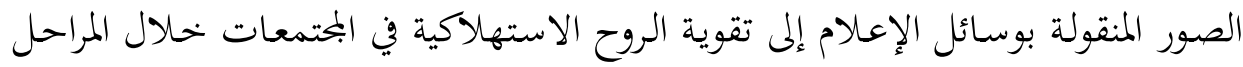

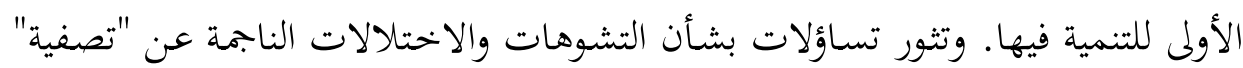

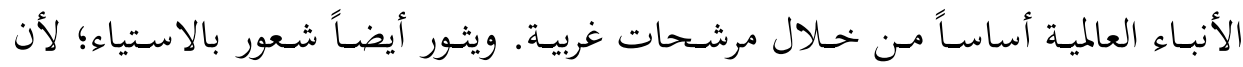

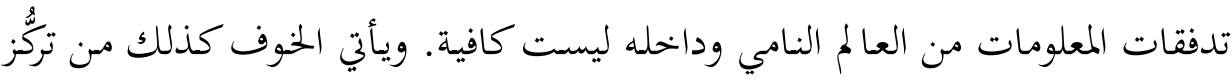

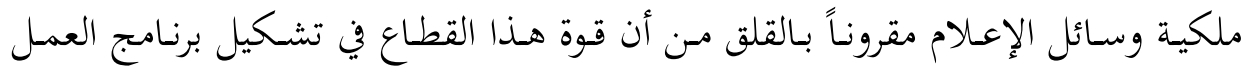

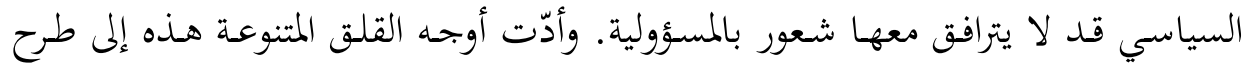

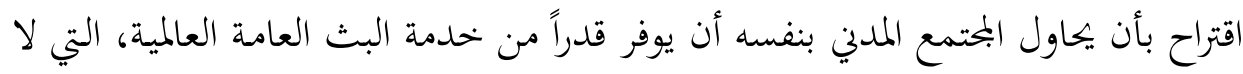

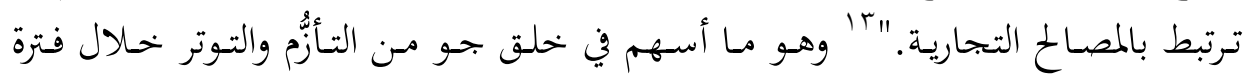

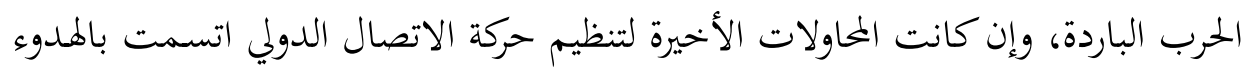

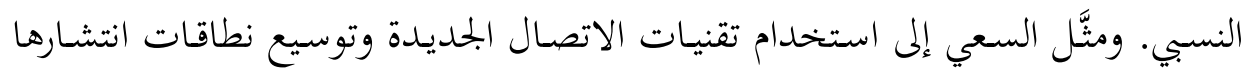
حركة إيجابية بين محوري الشمال والجنوب، وربما قللت الفجوة الرقمية القائمة بين المحورين

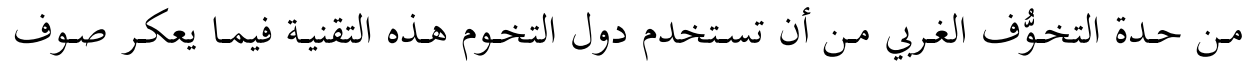

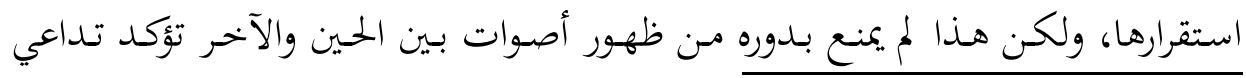

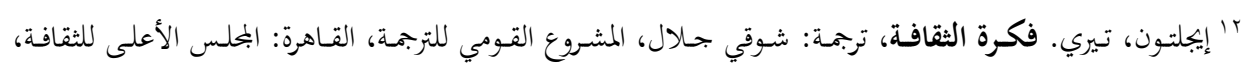
"ا لجنة إدارة شؤون الجُتمع العالمي. جيران في عالم واحـد، الكويت: البحلس الوطني للثقافة والفنون والآداب، 


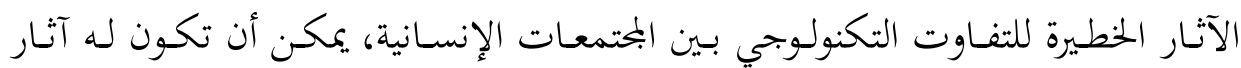

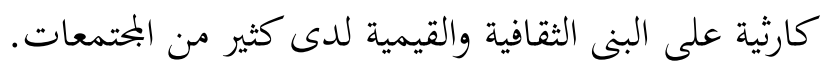

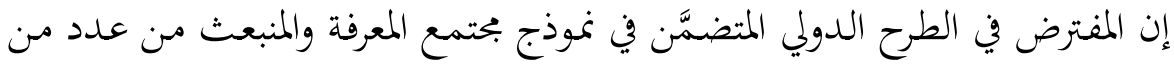

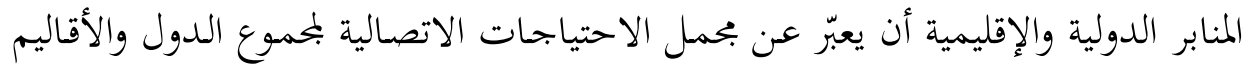

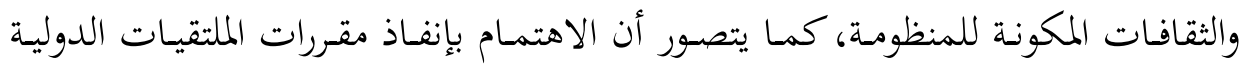

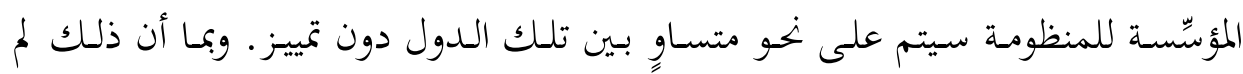

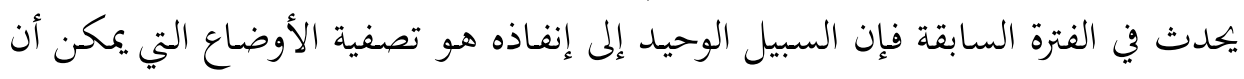
يكون في استمرارها تعزيز لمظاهر التحيز المختلفة.

ولكن مـا يقابل النـاظر في أحوال الاتصال الدولي مـن أوضاع لا يتفق متع مثالية

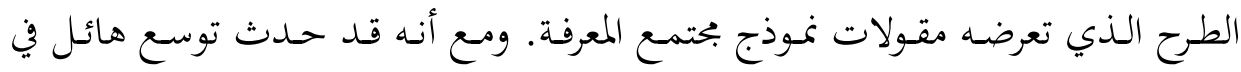

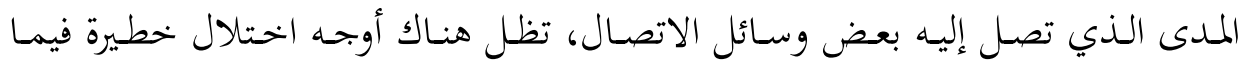

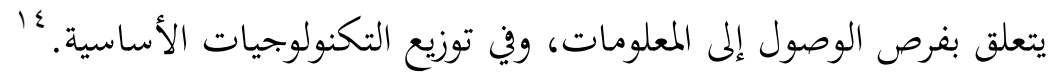

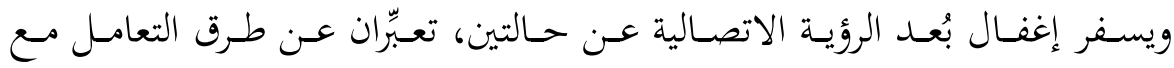

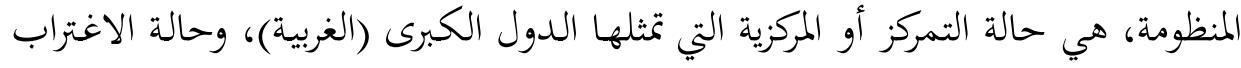

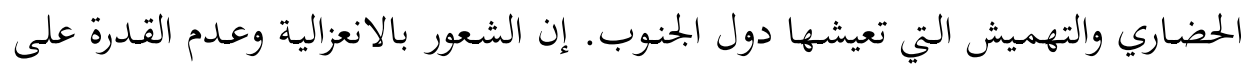

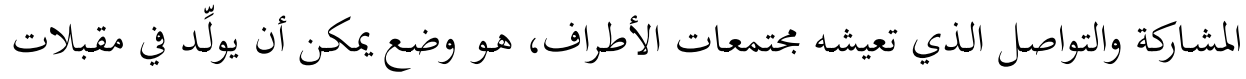

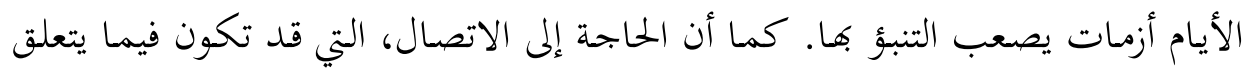

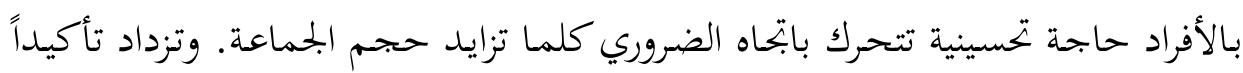

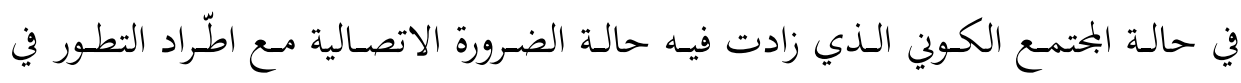

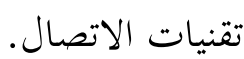

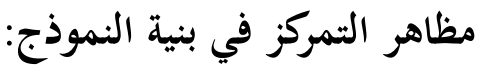

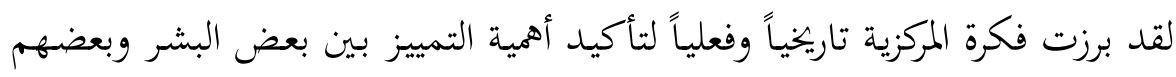

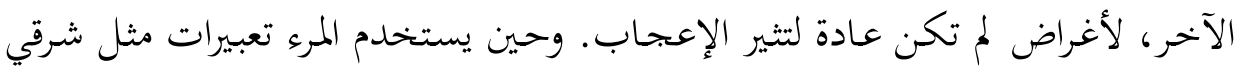


وغربي لتمثلَ نقـاطَ بدايـة وفهايـة للتحليـل والبحــث والسياسـة، فبإن النتيجـة عـادة هي استقطاب التمييز وتعميقه؛ إذ يصبح الشـرقي أكثر شرقية، والغربي أكثر غربيـة. ${ }^{1}$ إفـا

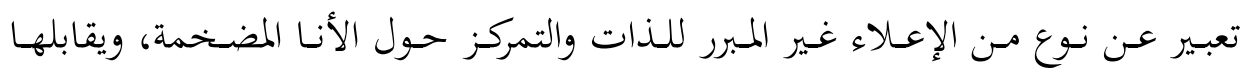
تمميش كامل للآخحر. إن هذا التحيّز الجلمي للمركزية الغربية في النمـاذج التنمويـة والعلوم الإنسانية الغربية يُفقِدِ محاولات الإنسان الغربي عولمة تلك النماذج والنظريات مشروعيتها ومنطقيتها في الوقت ذاته. وإضـافة إلى مـا سبقت الإشـارة له تـبرز معالم التمركز الغربي بوضوح في ظاهرة مهمة، هي ظاهرة التمركز اللغوي.

أ. التمركز اللغوي: تمثل حصة الشعوب المتحدثة بالإبحليزية . ب\%من بين إجمالي مستخدمي الإنترنتـ. ومع أنّ حصة الشعوب الأخـى مرشحة للزيـادة التدريجيـة خهلال السنوات المقبلة، فإنّ ذلك لن يتعارض مع سيادة الصبغة الإبحليزية للشبكة التي تكرّست

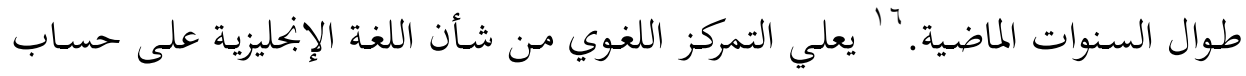

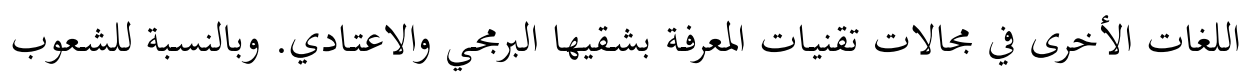

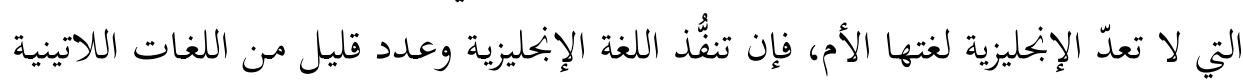

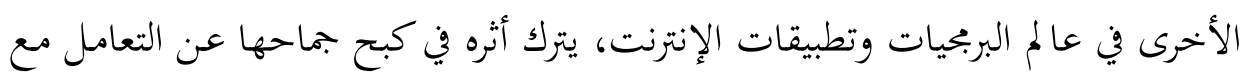

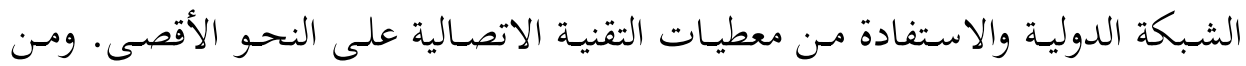
مظاهر التحيز والتمركز الغربي سيادة القيم الاتصالية الغربية، فهناك انتقاد مقدَّم مفاده أن أن القيم الحاكمة على حركة المعلومة ونشرها قد صيغت هي الأخرى على نهي نهو يعلي من القيم الاتصالية الغربية، التي تصنف على أها قيم منحازة في الأساس الذي تشكّلت به؛

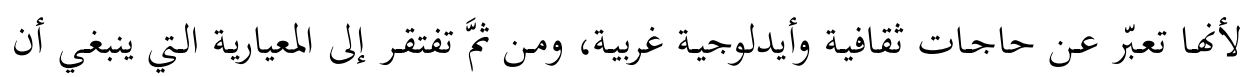
تكون سمة لأي نسق قيمي.

10 سعيد، إدوارد. الاستشراق: المعرفة، السلطة، الإنشاء، ترجمة: كمال أبو ديب، بيروت: مؤسسة الأبحاث العربية،

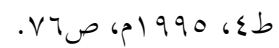
17 شاكر، حسام. المشكلات الثقافية فاقمت الفجوة التقنية بين الشمال والجنوب، رابط المقال: - http://www.onislam.net/arabic/madarik/culture-ideas/97776-2000-11-04\%2000-0000.html لا' ولنا هنا أن نتخذ ثلاثة نماذج للتحيز في صياغة القيم الحاكمة للنشاط الاتصالي: الأصولية والإرهاب وحقوق 
ب.الاغتراب الحضاري: تعيش بعض الأنساق الحضارية المقحمة في المنظومة حالة من الاغتراب الحضاري بجاه النموذج الحضاري الذي يعمل النظام على تعميمه؛ إذ ترتبط هيكلة النظام الاتصالي الدولي بظاهرة الاغتراب الحضاري على نهو عضوي، حيث بند

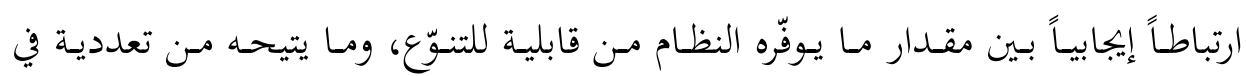
التمثيل، وبمقدار ما يراعيه من تكامل في الرؤية بين الخيارات الحضارية المختلفة. وقد أشار تقريـر (شـون ماكبرايـد) منـــ سـبعينات القـرن الماضـي إلى سمتـين تشـوبان حركـة التــفق

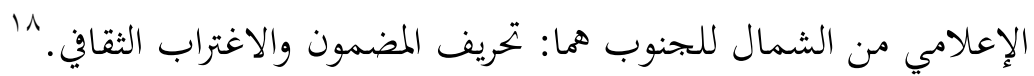

\section{خامساً: محددات بناء الرؤية الإسلامية للتواصل}

لمعالجـة مـا سبق عرضـه مـن إشـكالات متعلقـة بواقع التواصل الإنسـاني، لا بـدّ مـن وضع محـددات منهجيـة لبنـاء الرؤيـة التواصـلية القـادرة على تحقيـق الاستيعاب المنهجي المتجـــاوز لسـلبيات واقـع الفكــــ الاتصـالي السـائد. وقبـل ذلـك وأثنــاءه فــإن التواصـلية الإسلامية مطالبة بجملة من الإجراءات المنهجية، أهما:

\section{| استيعاب المعرفة التواصلية المعاصرة:}

تمثل ظاهرة التسـليم المطلق بنواتج علم الاتصال الغربي، والأمريكي منه على وجـه الخصـوص أحسد أشـكال التبعيـة التى قعّدت بحركة البحـث العلمي في الجحامعات العربيـة والإسـامية. إن هـذا النوع مـن القبول المطلق بنظريـات الاتصـال الغربية دون إخضـاعها للمراجعـة النقديـة والتقويم المنهجي، والتأكـد مـن قابليتها للتعمـيم النظري، والتوسّع في التفسير إلى نطاقات تتجاوز أطرها الميدانية، هو ما نددت به بعض الأصوات العربية وهي

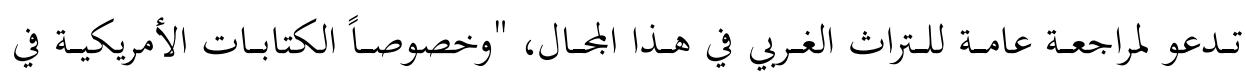

^\ ماكبرايد، شون وآخرون. أصسوات متعددة وعـالم واحسد، الجزائر: المؤسسة الوطنية للنشر وللتوزيع واليونسكو، 
الإعـام والتنميـة، وذلك بسبب تأثيرهـا الحاسـم على صسنَّاع القـرار السياسي والثقــافي والإعلامي في معظم دول العالم الثالث."

وموقف الرفض لناتج العلم الغربي دون إخضاع ظاهرة التخلُّف في هذه البحالات

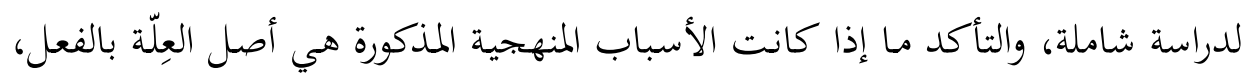

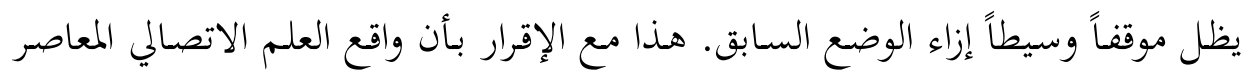

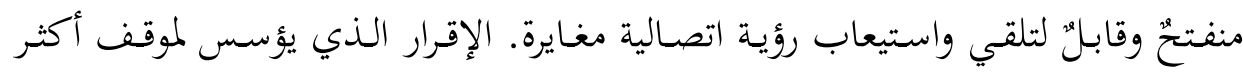

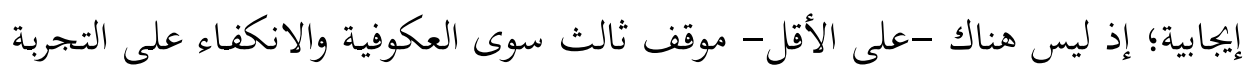

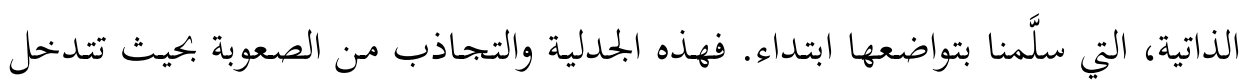

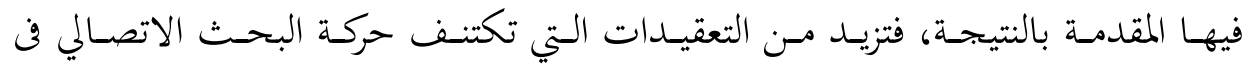
بجتمعاتنا العربية والإسلامية.

\section{r. الوعي المنهجي بالفضاء المفاهيمي للاتصال المعاصر:}

ذكرنا فيما سبق أن المقاربات النظرية لظاهرة الاتصال تصالحت في ثلاثة إشكال

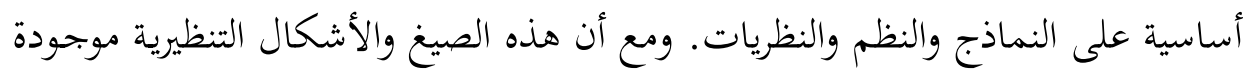

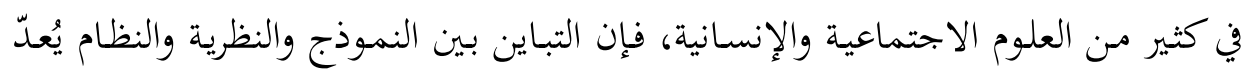

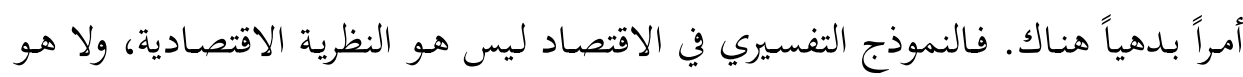

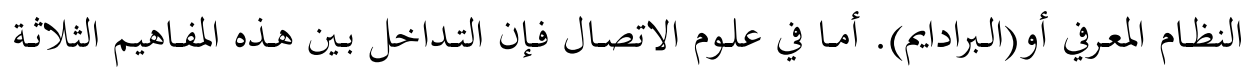

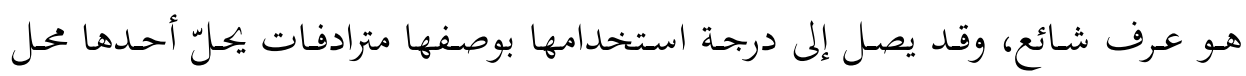

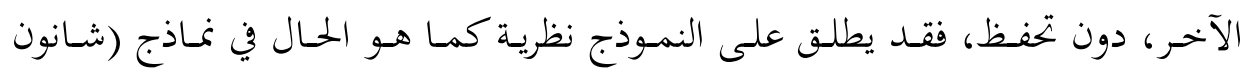

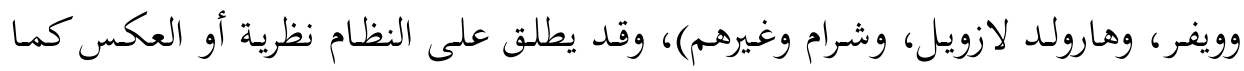

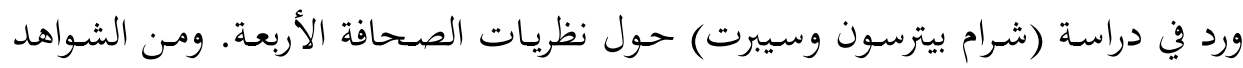

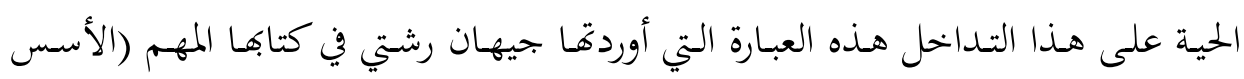

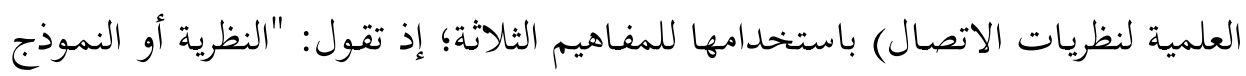
"19 عبد الرمن، عواطف. قضايا التبعية الإعلانية والثقافية في العالم الثالث، الكويت: المجلس القومي للثقافة، 
هي محاولة لتقديم العلاقات الكافية التي تفرض وجودها بين المتغيرات التى تضم حدثاً أو

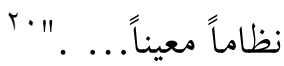

\section{ب. المساهمة في بلورة نظرية شاملة للاتصال:}

تعاني علوم الاتصال كما ذكرنا من غياب تفسير محدد للعملية الاتصالية. وإذاكان

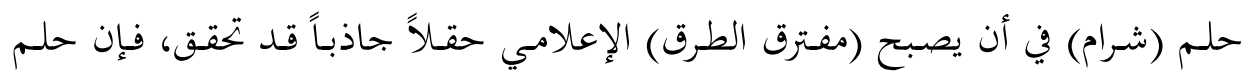
(ألبرت إنشتاين) بإيجاد نظرية للمجال الموحّد قادرة على تفسير كل الظواهر يبدو حلماً صعب التحقيق. وحقل علوم الاتصال والعلوم الاجتماعية دليل على ذلك، ففي "العلوم الاجتماعيـة يمكننـا أن نـرى العديـد مـن النظريـات التي تتعـايش وتتزاوج، ولكـن لا يوجـــ أنموذج علمي إلا إذا وجحدت نظرية قابلة للتحقق والاختبار يمكنها السيطرة علي غيرها من النظريات، وتحظي ككل بالقبول في الوسط العلمي. وفي بجال العلوم الاجتماعية لا توجد اكتشافات جوهريـة تتنـاول الأصول الأساسية لهذه العلوم على خهلاف الحسال في العلوم الاجتماعية، وبدلاً من ذلك يتم صياغة وبناء نظريات يتعذر اختبارها أو التحقق لونق مـ صحتها، ويرجع السبب في ذلك جزئياً إلى أن الواقع الاجتماعي يتغير بوتيرة أسرع

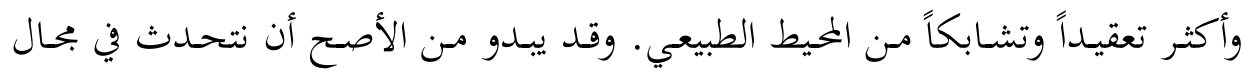

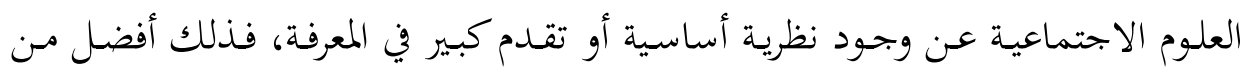
الادعـاء بوجسود نمـوذج علمسي ثابست فيها؛ لأن ذلك يقتضـي الإقـرار بوجسود مضـامين ودلالات نظرية غير متوافرة في العلوم التي لا تقوم على التجربة العلمية، لقد أصبح من

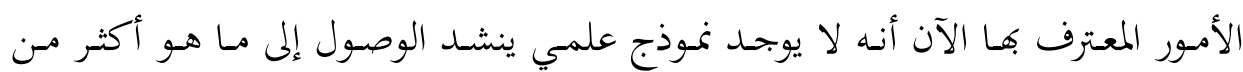

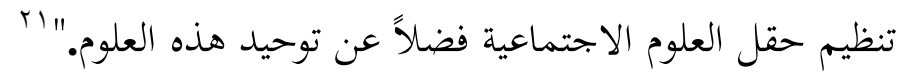

وإذا كنـا قـد قـدّمنا الحـديث حول المفـاهيم والنمـاذج والنظم والنظريـات، فلعل مـن المفيد مـن الناحية العمليـة أن نحاول تعريف النموذج العلمي وموقفه في بنـاء النظرية، ثم التعريف بالنموذج المعرين Paradigm. ويعدّ النموذج القياسي الذي تستند إلية النظرية

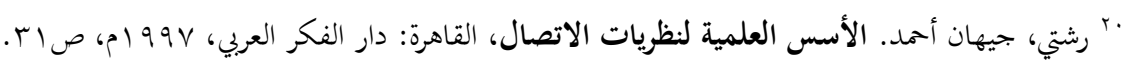

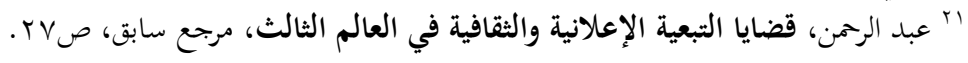


هـــو أول دعامـات النظريـة، وهـو ذلـك النمـوذج الـذي يشـتمل على الصـياغة الخاصـة

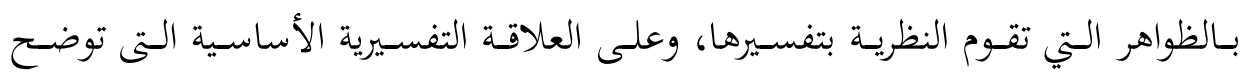
الأسلوب الذي تعمل بواسطته الظواهر.

\section{ع. التواصل مع الأنساق المعرفية الفاعلة في بنية العلم:}

من الطبيعي -نظراً للاختلاف العميق في المنطلقات الفكرية للعقل المسلم مع نظيره الغربي- أن تكون له رؤيته الخاصة لعلم الاتصال وظواهره. لقد ملئت المكتبة الإسلامية بنتـاج غزيـر مـن الدراسـات النظريـة البحتـة حـول قضـايا الاتصـال والإعـالام مـن المنظـور الإسلامي، ولكننا -على الأقل في وقتنا الراهن - لا نقوى على القول إن التنظير البحرد في بحال الأسلمة "عديم الفائدة"، ولكنه بكل المعايير "قليل الجمدوى"، فعلوم الاتصال ذات

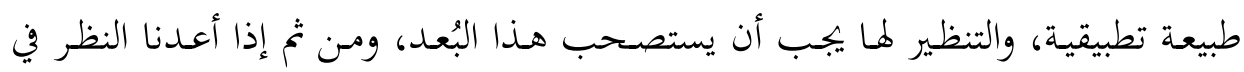
المجادلات العلمية سنجد أها تدعونا أولاً إلى تقويم الواقع التطبيقي.

ومسن هذه الزاوية يجبـ التسليم بأن ابتاهـات التأصيل النظري العربي والإسـامي لم

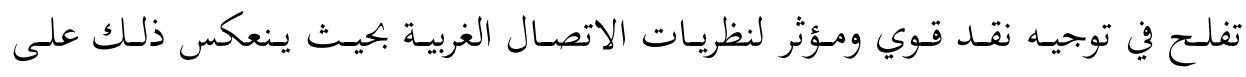

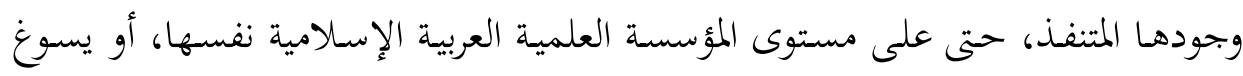
القبول المنطقي للبدائل النظرية التي تطرحها.

استندت محاولات التنظير إسلامياً - في تسويغها لأهمية التأصيل- إلى استشهادات

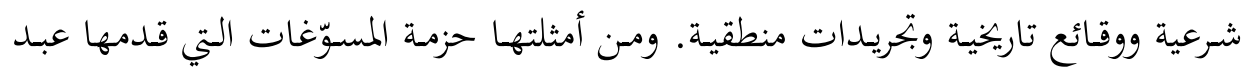
القـادر طـاث في مقاله: إضـاءات حـول الإعـلام الإسـلامي، الـذي نشـره ضـمن سلسـلة

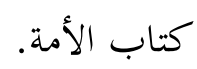

اتسمت التنظيرات الإسلامية بالتشتت الأفقي زماناً ومكاناً، وظلت على افتقارها إلى التراكم الضروري، وهو مـا يجعلنا نستغرب كون بعض التنظيرات الأقدم صدوراً بدت

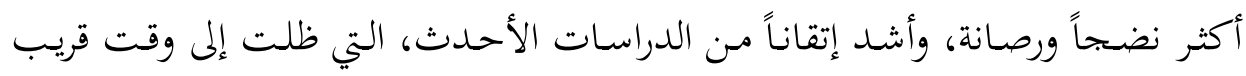
تتسم بالسطحية وضعف التأثير. 
ويلاحظ أيضاً أنه لم يتم استيعاب الاجتهادات الإسلامية في بحال النظرية الاتصالية

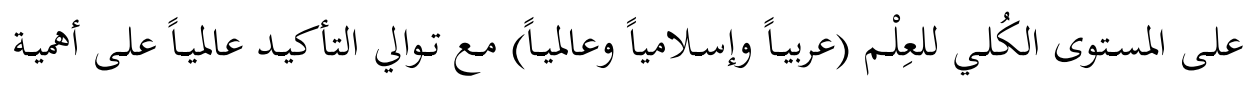
توسيع الأفق النظري لعلوم الاتصال. كما لم يتم استيعاب تلك الاجتهادات في صلب المؤسسة (الجامعية) في بلداها في هيئة مساقات دراسية أو كتب منهجية، أو برامج بحثية جادة وفاعلة.

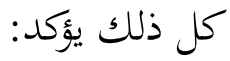

أ. أهمية وجود برنامج بحـث علمي في بحال أسلمة علوم الاتصال يعمل على أن ينظم الجهود التأصيلية في سياق كلي تراكمي، ويكفل لها الاستدامة. ب. أهمية استيعاب الاجتهادات التنظيةية في سياق المؤسسة الجامعية وكليات الإعلام في هيئة كتب منهجية، وهو أمر يستدعي المرور بثلاث مراحل: ا ـ رفـع مسـتوى التفاعـل العلمسي عـبر الملتقيـات الدوريـة الضـرورية، لمراجعـة تلـك الاجتهادات ومناقشتها على المستوى المحلي والإقليمي والعالمي. r الســي إلى النفـاذ بقضـايا الاتصـال الإسـالامي إلى مركـز اهتمامـات الجماعـة العلمية الاتصالية، ويجب أن نسلّم هنا أن هذا المركز يوجد الآن في الغرب. r. تشـجيع الدارسـين مسن خـارج الـدائرة الاسـلامية على دراسـة نظـم ونظريـات الاتصال الإسلامية، مما سيمنحها قدرة أكبر على النفاذ والمقبولية، ومن ثم يرفع من فرص الدول الإسلامية في المساهمة في إعادة توجيه المنظومة الكلية للاتصال الدولي.

خاتمة:

ووي الختام لا بدّ لمسألة الأسلمة والتأصيل من أن بتحد مكاهـا ضمن السياق الكلي للفكر الاتصالي العالمي، وبحرد محاولة التأسيس على أن النموذج التأصيلي هو نموذج قائم 
محمد بابكر العوض إIT

الاتصال والتواصل في منظومة بحتمع المعرفة

بذاته ومنعزل باهتماماته الخاصة عن الحركة الكلية لعلوم الاتصال، هو وضع غير طبيعي،

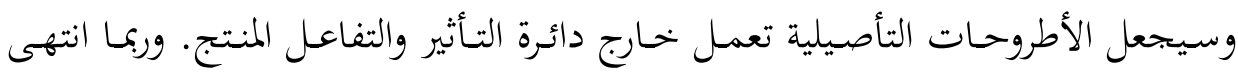
بالمحاولة التأصيلية إلى نمط إيدلوجي مغلق ومنغلق في الوقت ذاته، أو خيارٍ طرفٍٍ ميؤوس الدس

منه.

إن الطرح الإسلامي مطالب بأن يوجد لنفسه مكاناً في عمق بنية العلم الاتصالي،

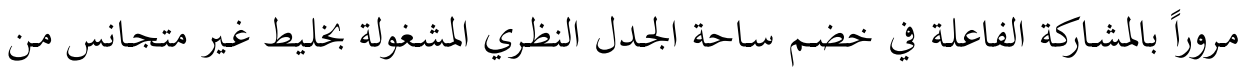
التوجهات والرؤى النظرية. والاستدراكات النقدية الإسلامية على الواقع الاتصالي يجب

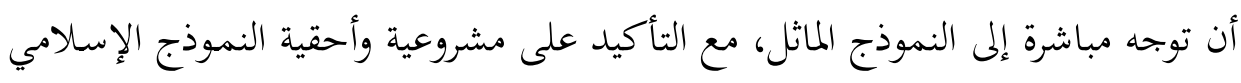
في أن يطرح نفسه بديلاً أو نموذجاً مقابلاً. 